\title{
4. Die Ära Karl Buschmann (1963-1978)
}

\subsection{Buschmanns Entspannungspolitik}

Ab 1963 stand die GTB eindeutig aufseiten der sozialpartnerschaftlich orientierten Gewerkschaften. Kritisch beäugt von der traditionalistisch orientierten Minderheit, die in den hoch organisierten Bezirken verankert war, richtete Karl Buschmann sein Angebot einer Zusammenarbeit an die Arbeitgeber und ihre Verbände. Diese reagierten verhalten, denn Buschmanns Vorschläge für eine sachliche Zusammenarbeit waren mit der Erwartung des Entgegenkommens auch der anderen Seite verbunden: Die Arbeitgeber sollten die Rolle der Gewerkschaften als Ordnungsfaktor nicht nur anerkennen, sondern auch durch Zugeständnisse honorieren.

Mit der Anerkennung der GTB als selbstverständliche Akteurin in der Branche sollte die Schlechterstellung ihrer Mitglieder teilweise ausgeglichen werden, die die Organisation mit ihren Beiträgen finanzierten, während die Nichtmitglieder auch ohne diesen Beitrag von den Tarifverträgen profitierten. Deshalb sollte es ausgewählte Tarifleistungen geben, die exklusiv nur Gewerkschaftsmitgliedern zugutekommen sollten. Wie bereits in der Lohnpolitik zeigte sich auch hier, dass Buschmann durch die Erfahrungen aus seinen USA-Studienreisen geprägt war. Dort hatte er die Praxis der »closed shops« kennengelernt, von denen während der Laufzeit von Tarifverträgen nur Gewerkschaftsmitglieder profitierten.

\subsubsection{Versachlichung - ein Angebot mit Bedingungen}

Karl Buschmann wurde 1963 mit 72,8 Prozent der Delegiertenstimmen zum neuen Vorsitzenden der GTB gewählt. Seine rechte Hand wurde Berthold Keller, der »Haudegen« des politischen Kurswechsels aus Baden-Württemberg. Unmittelbar nach seiner Wahl machte Buschmann deutlich, »daß wir uns an einem Wendepunkt unseres gemeinsamen Wirkens befinden«. Er formulierte einen deutlich 
erweiterten Anspruch seiner Gewerkschaft: »Nun treten wir an, seine [des arbeitenden Menschen] Anerkennung und seine geistige Freiheit zu verwirklichen. « ${ }^{1}$

Er forderte eine verstärkte politische Bildungsarbeit, da die Demokratie Menschen brauche, die mitdenken und handeln. Ein neues Verhältnis der Tarifvertragsparteien und eine versachlichte Austragung der Interessengegensätze seien erforderlich; die gemeinsame Verantwortung von Arbeitgebern und Gewerkschaft müsse zum Leitfaden werden, ohne dass diese sich als Vertragspartner überforderten. Beide Seiten sollten Diffamierung und Verunglimpfung einstellen. Die Wirkungsmöglichkeiten der Gewerkschaften - auch als einer Kraft, die das Grundgesetz bereit sei zu verteidigen - dürften nicht behindert werden und selbstverständlich müsse das Streikrecht unangetastet bleiben. ${ }^{2}$

Trotz ihrer Erfolge auf den Gewerkschaftstagen 1961 und 1963 war der reformerischen Mehrheit im GHV klar, dass der Flügel der »Traditionalisten« eingebunden werden musste. Deren Schwerpunkte lagen in den gewerkschaftlich hoch organisierten Regionen Norddeutschland, Ostwestfalen und Hessen. Buschmann griff die Erfahrungen aus dem Arbeitsalltag vieler Funktionär:innen auf und forderte Anerkennung nicht nur bei feierlichen Anlässen: „Es geht uns nicht um nette Worte - es geht uns um die Anerkennung in der Praxis.« Er erwartete, »daß in Zukunft sich mehr Arbeitgeber und Arbeitgeberverbände von diesem ehrlichen Wollen unserer Gewerkschaft überzeugen lassen. ${ }^{3}$

Nicht zuletzt, um die Kritiker aus den eigenen Reihen einzubinden, wurden den Arbeitgebern Bedingungen gestellt. Durch deren Erfüllung sollten sie die Ernsthaftigkeit ihres Interesses an einer Sozialpartnerschaft unter Beweis stellen und den Wandel der GTB zur marktwirtschaftlich-systemtragenden Organisation honorieren. Nach zweijähriger interner Diskussion verabschiedete der Gewerkschaftstag 1963 die neue GTB-Programmatik mit insgesamt neun »Anerkennungsforderungen«. Sobald wie möglich sollte tarifvertraglich vereinbart werden: ${ }^{4}$

- Beitragseinzug durch Lohnbüros

- zusätzliches Urlaubsgeld exklusiv für GTB-Mitglieder

- Unterstützungskassen für Beihilfen bei Krankheit, Alter und Invalidität

- Errichtung von Ferienheimen

1 GTB: Protokoll des 8. Gewerkschaftstages, 16.-20. September 1963 in Hannover, S. 150 (beide Zitate).

2 GTB: Protokoll des 8. Gewerkschaftstages, 16.-20. September 1963 in Hannover, S. 150.

3 GTB: Protokoll des 8. Cewerkschaftstages, 16.-20. September 1963 in Hannover, S. 65 (beide Zitate).

4 GTB: Protokoll des 8. Gewerkschaftstages, 16.-20. September 1963 in Hannover, S. 306 und 404. 
- Zusatzurlaub aufgrund von Alter, Branchenzugehörigkeit und Gewerkschaftsmitgliedschaft

- Geltungsbereich aller Tarifverträge nur für Mitglieder

- Schutz für Vertrauensleute

- bezahlte Freistellung von der Arbeit für Mitglieder von Tarifkommissionen

- Freistellung von Funktionären für Sitzungen, Konferenzen und Schulungen

Die GTB verfolgte damit die Strategie, aus der Rolle des »störenden Dritten« in die Funktion einer selbstverständlich dazugehörenden betrieblichen Akteurin zu wechseln. Mitsprache und Mitwirkung sollten die Interessen der Beschäftigten wirksam vertreten und durch die Befriedung interner Konflikte zugleich einen Beitrag zum wirtschaftlichen Gelingen der Unternehmen leisten. Die Umsetzung der Anerkennungsforderungen sollte die Gewerkschaft auch organisatorisch und finanziell entlasten.

Während es in der Nachkriegszeit weit verbreitete Praxis war, dass Gewerkschaftsbeiträge durch die Lohnbüros einbehalten und abgeführt wurden, lehnten die Arbeitgeber diese Unterstützung der Gewerkschaften seit Beginn der 1950er Jahre ab. Der nun erforderliche Verkauf von Beitragsmarken durch ehrenamtliche Kassierer:innen in den Betrieben war ein mühsames, oft nur mäßig funktionierendes Geschäft. Außerdem erhielten die Kassierer:innen 5 Prozent der Beiträge als Aufwandsentschädigung, was die Organisation zusätzlich belastete. Auch die Übernahme der Verdienstausfälle für Mitglieder von Tarifkommissionen stellte eine spürbare Belastung für die Gewerkschaft dar. Außerdem verweigerten die Arbeitgeber oft die unbezahlte Freistellung von gewerkschaftlichen Vertrauensleuten für Schulungen und Tagungen. Immer wieder berichteten selbst Delegierte auf Gewerkschaftstagen, dass sie für die Teilnahme tariflichen Urlaub nehmen mussten.

Die Mitgliederzahl war rückläufig und dass die Höhe der Gewerkschaftsbeiträge mit der Lohnentwicklung nicht Schritt hielt, wirkte zusätzlich finanziell belastend. Die negative Mitgliederentwicklung hatte verschiedene Gründe: Der mit der Gewerkschaftsmitgliedschaft verbundene höhere Schutz verlor mit dem Rückgang der Arbeitslosigkeit an Bedeutung. Gleiches galt für die traditionellen gewerkschaftlichen Unterstützungsleistungen für Kranke und Arbeitslose, da sozialstaatliche Leistungen zumindest die größten Härten ausglichen. Traditionelle milieubezogene Bindungen begannen sich zu lockern, $d$.h. man wurde nicht mehr Gewerkschaftsmitglied, weil auch der Vater und der Großvater Mitglieder waren.

Im Vergleich zu anderen Industriegewerkschaften litt die GTB zudem unter besonderen Strukturproblemen, denn in den vielen Kleinbetrieben gab es nur wenige vollständig von der Arbeit freigestellte Betriebsratsmitglieder. Der Großteil der Beschäftigten waren Frauen, die aufgrund des traditionellen Rollenver- 
ständnisses ein distanzierteres Verhältnis zu Gewerkschaften hatten. Außerdem sorgte der hohe Frauenanteil für eine starke Fluktuation in den Betrieben, weil viele Frauen ihre Berufstätigkeit nach der Heirat oder Geburt des ersten Kindes aufgaben. Die Fluktuationsrate der GTB-Mitglieder war doppelt so hoch wie die der IG Metall und die höchste innerhalb des DGB. ${ }^{5}$

Der entscheidende Punkt aber war, dass die Mehrheit der Beschäftigten die Früchte der Tarifpolitik wie kürzere Arbeitszeiten, längeren Urlaub und steigende Einkommen in Anspruch nahm, ohne dafür einen Beitrag zu leisten. Zwar galten und gelten Tarifverträge rechtlich nur für Mitglieder der tarifvertragsschließenden Parteien, sofern sie nicht durch die Arbeitsministerien für allgemeinverbindlich erklärt werden, aber die Arbeitgeber wenden Tarifverträge bis heute in der Regel für alle Beschäftigten und nicht nur für Gewerkschaftsmitglieder an.

Eine vergleichbare Diskussion über einen Ausgleich für Mitgliedsbeiträge gab es zeitgleich auch in der Industriegewerkschaft Bau-Steine-Erden (IG BSE). Deren Vorsitzender Georg Leber hatte zunächst einen Solidaritätsbeitrag der Nichtmitglieder für die Inanspruchnahme tariflicher Leistungen ins Gespräch gebracht, wie er in der Schweiz existierte und dort bis heute Praxis ist. An dieser Frage lasse sich entscheiden, ob die Reden der Arbeitgeber nur scheinheilig seien oder ob diese bereit seien, die Gewerkschaften in ihrer Ordnungsfunktion anzuerkennen. ${ }^{6}$ Neben IG BSE und GTB verfolgte auch die IG Bergbau und Energie diesen Kurs. Dass alle drei Industriegewerkschaften in Branchen tätig waren, die besondere strukturelle und wirtschaftliche Schwierigkeiten hatten, ist gewiss kein Zufall.

1962 gelang es Georg Leber unter Nutzung der tarifvertraglichen Sozialkassen, für das Baugewerbe ein besonderes Erholungsgeld ausschließlich für Gewerkschaftsmitglieder durchzusetzen. ${ }^{7}$ Otto Brenner, der Vorsitzende der IG Metall, befürchtete allerdings, dass Gewerkschaften durch solche von den Arbeitgebern zu gewährenden Regelungen in eine zu große Abhängigkeit geraten und ihre Unabhängigkeit verlieren könnten. ${ }^{8}$ Diese Skepsis teilte auch Werner Bock bis zu seinem Ausscheiden aus der GTB und hielt solche Regelungen darüber hinaus kaum für realisierbar. »Hüten wir uns davor in Wunschdenken zu verfallen «, erklärte er vor dem Beirat und warnte davor, nicht erfüllbare Forderungen zu postulieren. ${ }^{9}$

Das Arbeitgeberlager reagierte auf das GTB-Angebot zur Zusammenarbeit auf neuer Grundlage gespalten und das Vorurteil, dass mit der GTB sachlich nicht zu reden sei, geriet ins Wanken. Die »Tauben« unter den Arbeitgebern begrüßten

5 Armingeon (1988): Die Entwicklung der westdeutschen Cewerkschaften, Tabelle 4.8, S. 197.

6 CTB: Protokoll der Beiratssitzung vom 28./29. März 1961, AdsD 5/CTBA031002.

7 Gertschen (2013): Klassenfeinde-Branchenpartner?, S. 148.

8 DCB: Protokoll der Sitzung des Bundesvorstandes vom 7.3.1961, AdsD 5/DCA1000533.

9 CTB: Protokoll der Beiratssitzung vom 10./11. April 1963, ADSD 5/CTBA0301002. 
die Neuausrichtung der Gewerkschaft, aber das Misstrauen überwog. Die »Falken« sahen in den Vorschlägen trojanische Pferde, die in den Betrieben Einzug hielten, und fürchteten, die durch Akzeptanz der Anerkennungsforderungen gestärkte Gewerkschaft würde die Unternehmer an die Wand drücken. ${ }^{10}$

\subsubsection{Vom Gelingen und Scheitern der Anerkennungsforderungen}

Bereits im Jahr 1962 wollte die GTB die Arbeitgeber in der Bekleidungsindustrie auf die Probe stellen. Buschmann schätzte den Bundesverband Bekleidungsindustrie (BBI) gegenüber Gesamttextil als die »weichere Stelle« ein. Die Arbeitgeber dort galten als weniger konservativ, außerdem war die Bekleidungsindustrie eine wachsende Branche, die unter Arbeitskräftemangel litt. In der Modebranche war die Gewerkschaft streikunerfahren, doch konnten Produktionsstörungen die Bekleidungshersteller empfindlich treffen. Der designierte Vorsitzende Buschmann setzte trotz der Bedenken des noch amtierenden Vorsitzenden Bock durch, dass die GTB ohne bezifferte Lohnforderung in die Tarifrunde von 1962 ging und demonstrierte damit, dass die GTB ihren Fokus auf Anerkennungsforderungen und Urlaubsverlängerung legte. Schwerpunkt war eine Mitgliedervorteilsregelung in Form eines Urlaubsgeldes, das nur den GTB-Mitgliedern gezahlt werden sollte.

Die gewerkschaftliche Strategie, in dieser Branche anzusetzen, war zunächst erfolgreich. Es konnte ein Verhandlungsergebnis erzielt werden, das einige Punkte der Anerkennungsforderungen widerspiegelte: Die Gewerkschaftsbeiträge sollten direkt von den Lohnbüros der Unternehmen eingezogen werden, gewerkschaftliche Mitglieder der Tarifkommissionen sollten für deren Sitzungen und die Teilnahme an Tarifverhandlungen unter Fortzahlung der Bezüge von den Betrieben freigestellt werden. Es wurden Bestimmungen zugunsten gewerkschaftlicher Vertrauensleute vereinbart, die diese vor Repressalien wegen ihrer gewerkschaftlichen Betätigung schützen sollten. Aber das Verhandlungsergebnis hielt nur kurz, denn der BBI musste seine Zusage während der vereinbarten Widerrufsfrist zurückziehen, da die erforderliche Zustimmung von 85 Prozent in der außerordentlichen Mitgliederversammlung verfehlt wurde. ${ }^{11}$

Die GTB sprach von der Diktatur einer kleinen Minderheit und weigerte sich, die ursprünglich erzielte Einigung zu verschlechtern. Damit waren die Tarifverhandlungen auf Bundesebene gescheitert. ${ }^{12}$ Anschließend versuchte die GTB, ihre Forderungen auf regionaler Ebene durchzusetzen, was im Tarifgebiet Bayern

10 Vgl. Certschen (2013): Klassenfeinde-Branchenpartner?, S. 160-166.

11 CTB: Geschäftsbericht 1961-1962 des Hauptvorstandes, S. 66.

12 Seit 1950 gab es in der Bekleidungsindustrie zwar regionale Tarifverträge, die allerdings stets gemeinsam auf Bundesebene verhandelt wurden. 
bereits fünf Tage später gelang. Das ursprüngliche Verhandlungsergebnis wurde in kurzer Zeit in vier weiteren wichtigen Regionen der Bekleidungsindustrie durchgesetzt. Insgesamt profitierten davon rund 70 Prozent der Beschäftigten. ${ }^{13}$ Dadurch waren mit der Tarifrunde 1962 auch die seit 1950 bestehenden Bundestarifverhandlungen und Bundestarifverträge beendet; die Tarifpolitik für die Bekleidungsindustrie wurde jetzt regional weitergeführt.

So war schon Anfang 1963 ein Teil der Anerkennungsforderungen in der Bekleidungsbranche tariflich garantiert, bevor sie im Herbst vom Gewerkschaftstag als offizielle Programmatik beschlossen wurden. Der BBI wiederum war erst im Herbst 1962 in die "Schutzgemeinschaft der Arbeitgeberverbände der chemischen, der Metall- und der Textilindustrie« aufgenommen worden, deren Zweck die gegenseitige finanzielle Unterstützung in Arbeitskämpfen war, die branchenübergreifende tarifpolitische Interessen berühren. Die von der GTB mit den Regionalverbänden getroffenen Vereinbarungen reichten jedoch aus, dass die Schutzgemeinschaft den BBI wieder aus ihren Reihen ausschloss. ${ }^{14}$

Die GTB verfolgte die Linie der Anerkennungsforderungen weiter und kam 1963 einen großen Schritt voran. In diesem Jahr wurde nach gescheiterten Tarifverhandlungen und befristeten Streiks am 8. April mit dem Verband der saarländischen Textil- und Lederindustrie tarifvertraglich vereinbart, dass die Arbeitgeber 1 Prozent der Lohnsumme in eine von den Tarifvertragsparteien eingerichtete Kasse einzahlten, aus der ausschließlich Gewerkschaftsmitgliedern ein Erholungsgeld, also ein zusätzliches Urlaubsgeld in Höhe von jeweils 100-160 DM erhielten. Die Spitzenvereinigungen der Arbeitgeberzusammenschlüsse lehnten dagegen alle Anerkennungsforderungen der GTB und insbesondere die Differenzierungsklauseln zwischen Gewerkschaftsmitgliedern und Nichtmitgliedern ab. Konsequenterweise wurde der saarländische Textil- und Lederverband nach diesem Tarifabschluss aus der Arbeitsgemeinschaft der Arbeitgeberorganisationen des Saarlandes ausgeschlossen. ${ }^{15}$

Den größten Erfolg erzielte Karl Buschmann mit der erst 1961 gegründeten "Arbeitsgemeinschaft der Miederindustrie«. Dieser relativ kleine Arbeitgeberverband stand unter dem maßgeblichen Einfluss des Marktführers Triumph. 1963 schlossen die Tarifpartner eine grundlegende Vereinbarung, in der alle gewerkschaftlichen Anerkennungsforderungen berücksichtigt wurden. Die Arbeitgeber verpflichteten sich, jährlich 2,5 Prozent der Bruttolohnsumme an einen von der GTB gegründeten und ausschließlich von ihr kontrollierten »Verein Berufs- und Lebenshilfe für die Arbeitnehmer der Miederindustrie« abzuführen. Damit wurden Bildungs-, Gesundheitspräventions- und Erholungsmaßnahmen finanziert.

13 CTB: Geschäftsbericht 1961-1962 des Hauptvorstandes, S. 67.

14 Gertschen (2013): Klassenfeinde - Branchenpartner?, S. 164.

15 GTB: Ceschäftsbericht 1963-1964 des Hauptvorstandes, S. 212. 
Alle Beschäftigten erhielten von diesem Verein ein Erholungsgeld, dessen Höhe sich jeweils zur Hälfte nach der Dauer der Betriebs- und Gewerkschaftszugehörigkeit richtete. ${ }^{16}$

Im Dezember 1964 wurde das Tarifpaket in der Miederindustrie durch ein Schlichtungsabkommen ergänzt, das ein "Arbeitskampf-Vermeidungsabkommen" sein sollte: Beim Scheitern von Verhandlungen wurde automatisch eine öffentlich tagende Schlichtung initiiert; im Falle eines Arbeitskampfes sollten externe Beobachter:innen zu Urabstimmungen hinzugezogen werden, um Manipulationsvorwürfen von vornherein den Boden zu entziehen. Dieses Abkommen war in der Gewerkschaftsgeschichte einmalig.

Buschmann reagierte damit auf den wachsenden gesellschaftlichen Legitimationsdruck. Konservative Kräfte sahen in der guten Tarifentwicklung der frühen 1960er Jahre eine Gefahr, denn die Gewerkschaften waren durch die Vollbeschäftigung in einer starken Position. Nach dem Bau der Berliner Mauer verschärfte sich der Arbeitskräftemangel in Westdeutschland, da der Zustrom von Menschen aus der DDR abrupt endete. Zum Jahresende 1962 wandte sich Bundeswirtschaftsminister Ludwig Erhard über den Rundfunk mit einem dramatischen Appell »in einer schweren Stunde« an die Bevölkerung. Angesichts der hohen Lohnsteigerungen und zusätzlicher Arbeitszeitverkürzungen, die ein »Irrwahn" seien, forderte er zum »Maßhalten « auf. ${ }^{17}$

Um deutlich zu machen, dass sie nur sachbegründet handelt, hatte die GTB der Beteiligung der Öffentlichkeit an Tarifschlichtungsverhandlungen zugestimmt. Darüber hinaus vereinbarte sie regelmäßige Konsultationen außerhalb der Tarifrunden, um sowohl über wirtschaftliche Fragen als auch über betriebliche und überbetriebliche Konflikte zu beraten. Betriebliche Streitigkeiten sollten künftig nicht mehr über die im Betriebsverfassungsgesetz vorgesehene Einigungsstelle, sondern durch eine tarifliche Schlichtungsstelle entschieden werden, was Kosten und Zeit sparte.

Die Mitbestimmung bei der Festsetzung von Akkordsätzen wurde per Tarifvertrag von den Betriebsräten der Produktionsbetriebe auf eine tarifliche Akkordkommission übertragen. Die gewerkschaftlichen Mitglieder dieser Akkordkommission, die somit die Höhe der Akkordsätze mit der Lohnabteilung des Triumph-Konzerns verhandelte, wurden von der GTB benannt und vom Arbeitgeber unter Fortzahlung der Bezüge vollständig von der Arbeit freigestellt.

Bis zu dieser Vereinbarung hatte es in den über 50 Triumph-Produktionsbetrieben regelmäßig heftige Auseinandersetzungen über die Akkord-Leistungsvorgaben gegeben, die laut Betriebsverfassungsgesetz mit dem Betriebsrat für

16 CTB: Geschäftsbericht 1963-1964 des Hauptvorstandes, S. 239.

17 Schütz (2012): Vor 50 Jahren: Rundfunkansprache von Bundeswirtschaftsminister Ludwig Erhard. 
jeden Betrieb zu vereinbaren waren. Die GTB hatte die Betriebsräte im Ringen um gute Akkordvorgaben unterstützt und oft war eine Lösung erst durch Einigungsstellen erfolgt. Mit diesem Ringen um Löhne und Leistung hatte die GTB ihre Kompetenz unterstrichen. Da eine Schlichtung durch die Einigungsstelle für die Arbeitnehmerseite meist vorteilhafter war als das letzte "freiwillige « Angebot der Betriebsleitung, konnten die Betriebsräte und die sie unterstützende GTB diesen Erfolg für die Mitgliederwerbung nutzen.

Die tarifliche Akkordkommission, die nun den Aushandlungsprozess für die Arbeitnehmerseite gestaltete, kanalisierte fortan die Konflikte. Alle Akkordvorgaben wurden darüber hinaus nicht mehr betrieblich, sondern einmalig für den gesamten Konzern vereinbart. Durch die Mitgliedervorteilsregelung beim Erholungsgeld brauchte sich die GTB nicht mehr in betrieblichen Konflikten beweisen. Rückblickend kann festgestellt werden, dass die Entschärfung der Konflikte durch die tarifliche Schlichtung nicht zu Lasten der Beschäftigten ging, denn die Einkommensentwicklung verlief mindestens parallel zur Bekleidungsindustrie.

Grundlage dieses in der deutschen Tariflandschaft einmaligen Tarifpakets war das gemeinsame Interesse von Karl Buschmann und Herbert Braun, dem Geschäftsführenden Gesellschafter der Triumph AG, den Dauerkonflikt zu beenden und ein Fundament für ein kooperatives Miteinander zu legen. Der Mieder-Verbandssyndikus Karl Heinz Koch, CDU-Politiker und späterer hessischer Justizminister, hatte entscheidenden Anteil am Zustandekommen der Verträge. Über 25 Jahre hinweg war er die "graue Eminenz«, die bei sich abzeichnenden größeren Tarifkonflikten Brücken baute.

Seit Abschluss dieses Tarifpakets haben weder die GTB noch ab 1998 die IG Metall die Tarifverträge für die Miederindustrie gekündigt. Das bedeutet auch, dass während der Verhandlungen die Friedenspflicht gilt und die Gewerkschaft nicht zu Warnstreiks aufrufen darf. Die Tarifergebnisse orientierten sich bis 2006 in der Regel an denen der Bekleidungsindustrie und werden seither eigenständig weiterentwickelt. In den 1960er Jahren stieg der Organisationsgrad in den Produktionsbetrieben von Triumph auf über 90 Prozent und lag auch bei den nach Tarifvertrag bezahlten Angestellten deutlich oberhalb des Branchendurchschnitts.

Die GTB nutzte einen Teil der an den »Verein Berufs- und Lebenshilfe« gezahlten Beiträge, um den Beschäftigten mit der 1964 gegründeten "Stiftung zur Förderung von Bildung und Erholung der Arbeitnehmer der Miederindustrie« politische Bildungsangebote zu unterbreiten. In den 1970er Jahren erreichte die GTB eine Erhöhung der Arbeitgeberleistung von 2,5 auf 4 Prozent der jährlichen Bruttolohn- und gehaltssumme. Mit diesen Mitteln wurde eine eigene Erwachsenenbildungseinrichtung gegründet: die 1977 eröffnete »Kritische Akademie« im oberbayerischen Inzell (siehe Kapitel 4.2). Seitdem profitieren jährlich 25-35 Prozent der Beschäftigten der Miederindustrie von diesem Tarifvertrag und bilden 
sich in Seminaren und sogenannten Gesundheitswochen fort. ${ }^{18}$ Das Erholungsgeld wurde zwar 2002/2003 abgeschafft und seitdem fließen die Mittel in eine zusätzliche betriebliche Altersversorgung. Aber auch hier werden Gewerkschaftsmitglieder bessergestellt als Nichtmitglieder.

In den Jahrzehnten seit Abschluss des Mieder-Tarifvertrags hat sich nicht nur die Welt der Bekleidungsproduktion grundlegend verändert. Auch bei dessen maßgeblichem Unternehmen, der Triumph AG, arbeiteten 1998 von insgesamt 40.000 Beschäftigten nur noch gut 2.000 in Deutschland; der Sitz der Konzernzentrale wurde inzwischen in die Schweiz verlegt. Obwohl die speziellen Tarifregelungen für Deutschland also nur noch von geringer Bedeutung für den Unternehmenserfolg waren, wurden sie erst zaghaft, dann immer deutlicher infrage gestellt. Die gewerkschaftliche Tarifkommission machte jedoch deutlich, dass man sich weder die Bildungsmöglichkeiten noch die Mitgliedervorteilsregelungen nehmen lasse. Daher konnten die besonderen Tarifregelungen 2011 nach einigen Jahren der Unsicherheit, in denen das Mieder-Tarifpaket immer wieder zur Disposition stand, für die kommenden zehn Jahre festgeschrieben werden.

\subsubsection{Streit und Streik um Mitgliedervorteile}

Gesamttextil und Bundesverband Bekleidungsindustrie (BBI) lehnten jede Differenzierung von Tarifleistungen entschieden ab. Der weitaus stärker von der Gegnerschaft zur Gewerkschaft geprägten Textilindustrie gingen die seit 1963 geltenden verpflichtenden Bekleidungsregelungen $\mathrm{zu}$ weit. Dies betraf insbesondere den Beitragsabzug durch die Lohnbüros und die Freistellungsregelungen für Tarifkommissionsmitglieder. Die Arbeitgeberverbände für Hessen und Rheinland-Pfalz sahen es bereits als großes Entgegenkommen an, dass sie die Verbandsbeschlüsse über das Verbot des Einzugs von Gewerkschaftsbeiträgen aufhoben. Buschmanns Hoffnung, dass mit den Vereinbarungen im Saarland und für die Miederindustrie ein Durchbruch erzielt sei, dem zumindest die Bekleidungsindustrie folgen würde, erfüllte sich nicht.

Nachdem auch im Jahr 1964 noch keine tarifvertragliche Lösung in Sachen Nachteilsausgleich für die Beitragsleistung der Gewerkschaftsmitglieder erreicht werden konnte, sollten nun Nägel mit Köpfen gemacht werden. Für die Tarifrunde 1965 beschloss die GTB, im Rahmen ihrer 9-Prozent-Forderung auch ein exklusives Urlaubsgeld für Mitglieder in der gesamten Bekleidungsindustrie zu fordern. Wie in der Miederindustrie sollten die Arbeitgeber 1 Prozent der Lohn- und

18 Vgl. hierzu die Geschäftsberichte 1965-2017 der»Stiftung Bildung, Erholung, Gesundheit«, vormals »Stiftung zur Förderung von Bildung und Erholung der Arbeitnehmer in der Miederindustrie«. 
Gehaltssumme in eine Kasse einzahlen, aus der die Beschäftigten ein Urlaubsgeld erhalten sollten. ${ }^{19}$

Die Arbeitgeberverbände lehnten diese Forderung nicht nur grundsätzlich ab, sie hielten das Anliegen auch für rechtswidrig und es kam zu einem regelrechten Gutachterstreit. Der erste Präsident des Bundesarbeitsgerichts, Hans Carl Nipperdey, gab den Arbeitgebern in einer Stellungnahme recht, nachdem er zuvor eine andere Ansicht vertreten hatte. Die Juristen Friedhelm Farthmann und Erich Fechner sowie Franz Gamillscheg, Leiter des renommierten Instituts für Arbeitsrecht an der Universität Göttingen, unterstützten die Position der GTB. Kern des Streits war die negative Koalitionsfreiheit, also das Recht, der Gewerkschaft nicht beitreten zu müssen. Gamillschegs Zusammenfassung lautete:

»So lange der Vorteil, den der Außenseiter nicht erhält, nicht einmal die Kosten seines Beitrages zur Gewerkschaft erreicht, den er ja spart, dann ist selbst von irgendeinem Zwang ernsthaft nicht zu reden. « $^{20}$

Ausgerechnet die GTB, die sich eine kooperative Politik auf die Fahnen geschrieben hatte, entfachte mit ihrer Forderung nach einer Tarifregelung als Nachteilsausgleich für Gewerkschaftsmitglieder einen Grundsatzkonflikt. Anfang 1965 scheiterten die regionalen Verhandlungen für die Bekleidungsindustrie in Westfalen und Bayern, woraufhin der GTB-Hauptvorstand am 25. Februar 1965 beschloss, Urabstimmungen über einen Streik in diesen Tarifbezirken durchzuführen. Siegessicher erklärte der Hauptvorstand:

»Wir zweifeln nicht daran, dass es gelingen wird, den zentral gesteuerten Widerstand der Arbeitgeber zu brechen. Wir passen unser Verhalten nun der schroffen Ablehnung der Arbeitgeber an. Wer sich weigert, die Ordnungsfunktion der Cewerkschaft durch eine materielle Würdigung ihrer Mitglieder anzuerkennen, der muss auch die Verantwortung übernehmen, wenn diese Ordnung bei einer ernsthaften Cefährdung des Arbeitsfriedens verloren geht. ${ }^{21}$

In Bayern waren zunächst 11 Betriebe für den Streik vorgesehen, in Westfalen 19. Bevor der Streik begann, schlossen bereits 15 Betriebe einen Haustarifvertrag ab, in dem sie sich zu den Zahlungen in eine Urlaubskasse verpflichteten. Damit verließen wichtige Arbeitgeber die Verbandslinie, um wirtschaftliche Schäden durch einen Arbeitskampf zu vermeiden. Dies hatte offensichtlich Priorität gegenüber ideologischen Begründungen, aber auch gegenüber der Verbandssolidarität mit

19 CTB: Geschäftsbericht 1965-1967 des Hauptvorstandes, S. 305.

20 Camillscheg (1966): Die Differenzierung nach der Cewerkschaftszugehörigkeit, Berlin, S. 63.

21 GTB: Presseerklärung vom 22. Februar 1965, AdsD 5/CTBA410294. 
Konkurrenten, die weiterhin unnachgiebig blieben. Als die Streiks Ende Februar/ Anfang März 1965 begannen, hatten sich bereits 40 Unternehmen per Haustarifvertrag zur differenzierten Urlaubsgeldzahlung verpflichtet. ${ }^{22}$ Einer der Großen der Branche, der trotz guter gewerkschaftlicher Organisation der Linie des Arbeitgeberverbandes treu blieb, war der Bekleidungshersteller F.W. Brinkmann in Herford. Dieses Unternehmen sowie vier weitere Betriebe in Westfalen und ein Betrieb in Bayern wurden wochenlang bestreikt.

Strukturell entstand ein Patt. Angesichts des »Einknickens« vieler Unternehmen lag eine flächendeckende Aussperrung außerhalb der Möglichkeiten der Arbeitgeber. Aber auch die GTB konnte angesichts der vielen Haustarifverträge in ihren »Kampfbetrieben« kaum etwas zulegen, um den Arbeitgeberverband stärker unter Druck zu setzen. ${ }^{23}$ So wurde dieser Tarifkonflikt mit nur rund tausend Streikenden ausgetragen. Auch wenn der Streik volks- und branchenwirtschaftlich eher unbedeutend war, fand er doch bundesweite Beachtung. Presse und Rundfunk berichteten ausgiebig und jede Seite versuchte, die Öffentlichkeit für sich zu gewinnen. Die GTB unterstrich ihr Vorgehen als sachorientiert ${ }^{24}$ und hatte dafür schon im Vorfeld viel Verständnis gefunden. So fragte der Journalist Alfred Horné im Bayerischen Rundfunk:

»Was meinen denn nun die Arbeitgeber mit der >Ordnungsfunktion der Cewerkschaften<, mit der >Anerkennung des gleichberechtigten Verhandlungspartners<, mit der >vertrauensvollen Zusammenarbeit<, mit >der Partnerschaft?? Wenn das nicht alles pure Quacksalberei sein soll, wenn die Partnerschaft unser sozialpolitisches Feiertagsdeutsch nicht lediglich um eine noch nicht einmal ganz neue Vokabel bereichern soll - dann muss doch in schlichter Alltagssprache gefragt werden: Nun, liebe Arbeitgeber, heraus mit der Sprache, was wollt Ihr denn eigentlich? [...] Wenn die bisherige Praxis die Marschroute der Arbeitgeber bleiben soll, dann müssen sie - bitteschön - auf das Gerede von Partnerschaft verzichten. ${ }^{25}$

Sogar die Frankfurter Allgemeine Zeitung konnte die Gewerkschaftsforderung nachvollziehen, ${ }^{26}$ ebenso die Stuttgarter Zeitung, die schrieb:

22 Aufstellung der GTB, in: GTB: Tarifakten 1965, AdsD 5/CTBA410294.

23 Vgl. Handelsblatt (1965): Cespaltenes Arbeitgeberlager, in: Ausgabe vom 10.3.1965.

24 GTB: Pressenachrichten vom 30. April 1965, AdsD 5/GTBA410294.

25 Horné (1964): Sozialpolitischer Kommentar.

26 Frankfurter Allgemeine Zeitung (1965): Der Kleinkrieg der IC Textil, in: Ausgabe vom 15.3.1965. 
»Durch Neinsagen wird diese Bewegung nicht zum Stillstand gebracht werden und die Anerkennungsforderungen werden hintenherum über die Betriebe kommen. Was nutzt es da dem Dachverband, wenn er die Fahne hochhält?«27

Auf der anderen Seite verglich das BDA-Magazin "Der Arbeitgeber" die GTBForderung mit der Erpressung von Schutzgeldern. ${ }^{28}$ Viele Solidaritätsadressen erreichten die Streikenden, darunter eine ganze Reihe aus dem Ausland, wo Mitgliedervorteile eine Selbstverständlichkeit waren, z. B. in Skandinavien, den Niederlanden oder Belgien. Die Versuche der Arbeitsminister von Bayern und Nordrhein-Westfalen, den Konflikt zu schlichten, scheiterten mehrfach. Bestreikte Arbeitgeber verschärften die Lage, indem sie Streikende »auflösend aussperrten « und damit sofort entließen. ${ }^{29}$ Nach mehreren Wochen begann die Streikfront zu bröckeln. Zaghafte Versuche der GTB, den Arbeitskampf auszuweiten, brachten nur wenig Erfolg. Einige Unternehmen schlossen weitere Haustarifverträge $a b$, in anderen mittelgroßen Betrieben verfehlte die GTB die erforderliche 75-prozentige Zustimmung der Mitglieder für einen Streik. ${ }^{30}$

Neben der Arbeitskampfsituation gewann die rechtliche Auseinandersetzung über die Zulässigkeit der Gewerkschaftsforderungen zunehmend an Bedeutung. Am 31. März 1965 gab es ein ermutigendes Zeichen: Das Arbeitsgericht Saarbrücken wies die Klage eines Mitglieds der Christlichen Textilgewerkschaft auf zusätzliches Urlaubsgeld ab, das gemäß der dortigen Tarifregelung nur an GTB-Mitglieder ausgezahlt wurde. Gemeinsame Kassen der Tarifvertragsparteien seien auch dann rechtens, wenn Nichtorganisierte von den Vorteilen ausgeschlossen seien. ${ }^{31}$

Nach über zehn Wochen Streik machte sich Anfang Mai in der GTB Nervosität breit. Bezirksleiter aus nicht am Streik beteiligten Tarifgebieten berichteten, dass die Mitglieder Lohnerhöhungen erwarteten, und sahen keine Chance mehr, die flächendeckende Mitgliedervorteilsregelung durchzusetzen. Sie wollten ein Ende der Auseinandersetzung, weil sie vor einer Lösung in den Streikbezirken Bayern und Westfalen keine Tarifverträge abschließen durften - so hatte man sich vor

27 Stuttgarter Zeitung (1965): Stoß vom Trittbrett, in: Ausgabe vom 31.3.1965.

28 BDA (1965): Der Arbeitgeber, Sonderausgabe vom 20.3.1965.

29 Bei der »lösenden Aussperrung« ruhen nicht nur wie bei der »suspendieren Aussperrung« die Hauptpflichten aus dem Arbeitsvertrag, sondern das Arbeitsverhältnis wird fristlos ohne Kündigung durch den Arbeitgeber beendet. Das Bundesarbeitsgericht hat diese Maßnahme 1971 im Grundsatz für zulässig erklärt, ihr aber enge Grenzen gesetzt. In der Praxis spielt die lösende Aussperrung heute keine Rolle mehr; vgl. Schumacher (o. J.).

30 So bei der Firma Seidensticker in Bielefeld; vgl. GTB (1965): Tarifreport, Nr. 5 vom 29.3.1965, AdsD 5/GTBA410294.

31 Westdeutsche Allgemeine Zeitung (1965): Organisierten steht Extrarecht zu, in: Ausgabe vom 1.4.1965. 
Streikbeginn verständigt. In einer Sondersitzung diskutierte der GHV mit den Bezirksleitern über Durchhalten oder Aufgeben. Vorgeschlagen wurde ein Kompromiss, der statt Urlaubskassen die Gründung eines paritätisch verwalteten Bildungswerks vorsah, das von den Arbeitgebern finanziert werden sollte.

Der ostwestfälische Bezirksleiter Oskar Stieghorst stand mit "seinem《 Arbeitskampf alleine da. »Der Ofen ist aus«, stellte auch der nordbayerische Bezirksleiter Harry Gösel fest. Otto Haas aus Baden-Württemberg sah keine andere Möglichkeit, als auf alle Anerkennungsforderungen - sowohl Urlaubskasse wie Bildungswerk - zu verzichten. ${ }^{32}$ Am zweiten Tag platzte die Nachricht in die Sitzung, dass das Arbeitsgericht Düsseldorf den Streik bei der Firma F.W. Brinkmann in Herford per einstweiliger Verfügung untersagt hatte. Formal ging es um die Frage, ob die GTB dafür streiken dürfe, am Ende des Arbeitskampfes von Schadenersatzforderungen freigestellt $\mathrm{zu}$ werden. Dieses Streikziel hielt das Arbeitsgericht für rechtswidrig. ${ }^{33}$ Aus dem Verhandlungsverlauf ließ sich schließen, dass das Gericht auch die Forderung nach einer Mitgliedervorteilsregelung kritisch bewertete.

Nach dieser Entscheidung waren die Arbeitgeber im Vorteil, auch wenn die einstweilige Verfügung zunächst nur ein Unternehmen betraf. Die GTB führte den Streik in den anderen Betrieben weiter, verzichtete jedoch auf die Forderung einer Mitgliedervorteilsregelung. So konnten die Arbeitskämpfe im Laufe des Mai beendet werden. Bei den Herforder Streikbetrieben F.W. Brinkmann und Angenete \& Scholle wurde eine dreistellige Zahl von aktiven Gewerkschafter:innen nicht wiedereingestellt oder wollte nicht an den alten Arbeitsplatz zurückkehren. Die gute Konjunktur führte dazu, dass die meisten Entlassenen rasch wieder Arbeit fanden. Mitte Juli, rund acht Wochen nach Ende der Streiks, waren in Herford von den 353 Streikenden in beiden Unternehmen bereits 310 wieder beschäftigt, allerdings nur 123 in ihren bisherigen Betrieben. ${ }^{34}$

Die gerichtlichen Auseinandersetzungen dauerten an. Auch im Hauptverfahren wurde der Streik als rechtswidrig eingestuft und auf Antrag des westfälischen Bekleidungsverbandes wurden die abgeschlossenen Firmentarifverträge ebenfalls für nichtig erklärt. Im Jahr 1967 bestätigte das Bundesarbeitsgericht die Rechtswidrigkeit der Tarifforderung letztinstanzlich, als es aus Artikel 9 Absatz 3 Grundgesetz eine negative Koalitionsfreiheit kreierte, die es durch die Tarifforderung verletzt sah. Im November 1967 entschied der Große Senat des Bundesarbeitsgerichts, dass in Tarifverträgen nicht zwischen den bei der vertrag-

32 Keller, Berthold: Handschriftliche Notizen von der Sitzung des GHV mit den Bezirksleitern am 6./7.Mai 1965, AdsD 5/GTBA410294.

33 Vgl. GTB (1965): Tarifreport Nr. 9 vom 10.5.1965, AdsD 5/CTBA410294.

34 Trost, Paul: Handschriftliche Aktennotiz vom 26.7.1965, AdsD 5/GTBA410254 (Paul Trost war der Kassierer der GTB). 
schließenden Gewerkschaft organisierten und anders oder nicht organisierten Arbeitnehmer:innen differenziert werden darf. ${ }^{35}$

Schadenersatzklagen der bestreikten Unternehmen blieben jedoch erfolglos. Da sich die GTB auf Rechtsgutachten maßgeblicher Arbeitsrechtler gestützt hatte, war ihr kein willkürlich rechtswidriges Handeln nachzuweisen. Die 1963 vereinbarten Vorteilsregelungen für Mitglieder im Saarland und in der Miederindustrie wurden nicht gekündigt und auch nicht durch Arbeitsgerichte beanstandet. Unabhängig von der Rechtsprechung bestanden also Lösungsmöglichkeiten für differenzierte Tarifvertragsleistungen, wenn die Arbeitgeberverbände zugestimmt hätten. Jahrzehnte später relativierte das Bundesarbeitsgericht die Rechtsprechung und bestätigte 2014 die Zulässigkeit exklusiver Tarifleistungen für Gewerkschaftsmitglieder. ${ }^{36}$

Die Mitgliedervorteilsregelung sollte den Weg der Sozialpartnerschaft ebnen - das per Streik zu erzwingen erscheint paradox. Die Forderung nach einem »Nachteilsausgleich« für die Zahlung des Gewerkschaftsbeitrags war in der GTB populär, hätte die Erfüllung doch die Mitgliederwerbung sehr erleichtert. Die Tarifkommissionen betonten mit der Forderung nach den Exklusivleistungen die Ernsthaftigkeit der Anerkennungsforderungen,- sicher nicht ohne Einfluss der Buschmann-Kritiker. Die zum traditionalistischen Flügel zählenden westfälischen Bezirke standen dem Partnerschaftsgedanken zwar kritisch gegenüber, erkannten aber durchaus die Vorteile, wenn die Anerkennungsforderungen umgesetzt würden. Die erleichterte Mitgliederwerbung würde den Organisationsgrad erhöhen und dann auch bessere Handlungsspielräume für gewerkschaftliche Aktivitäten schaffen.

Im Rückblick scheinen die grundsätzliche Strategie und die Taktik des Arbeitskampfes nicht ausreichend durchdacht. Den Widerstand gegen Arbeitszeitverkürzungen konnte man in Zeiten gut laufender Konjunktur zur Not mit einigen Streiktagen brechen, aber die GTB-Führung hatte unterschätzt, dass es bei den Mitgliedervorteilsregelungen um mehr ging. Zwanzig Jahre nach dem Arbeitskonflikt erklärte Karl Buschmann, bahnbrechende Tarifverträge könne man eben nicht erstreiken. »Der Weg dazu führt nur über Gespräche, die gegenseitige Achtung und Anerkennung zur Voraussetzung haben. ${ }^{37}$ Offen bleibt, ob Buschmann mit dem Arbeitskampf 1965 ein Scheitern seiner innergewerkschaftlichen Widersacher bewusst in Kauf nahm. Dagegen spricht aber, dass sich die GTB-Führung für eine Klärung der Frage der Mitgliedervorteilsregelungen bis

35 BAG, 29.11.1967-CS 1/67.

36 BAC 4 AZR 50/13 zu IC Metall-Mitgliedervorteilsregelungen bei der Adam Opel $\mathrm{CmbH}$.

37 textil-bekleidung, Ausgabe 12/1984, S. 14. 
hin zum Bundesverfassungsgericht einsetzte. ${ }^{38}$ Das höchste deutsche Gericht verwarf im Jahr 1971 die Verfassungsbeschwerde der GTB als unzulässig. ${ }^{39}$

\subsubsection{Trotz Friedensangeboten weiter im Kampfmodus}

Trotz der vollzogenen Richtungsänderung blieb die Tarifpolitik nicht nur in Sachen Anerkennungsforderungen konfliktreich. Die Durchschnittslöhne in der Textilindustrie wiesen für die Jahre 1963 und 1964 ein kräftiges Plus von insgesamt 19,6 Prozent aus, in der Bekleidungsindustrie stiegen sie um 14,6 Prozent obwohl sich die Lebenshaltungskosten in beiden Jahren nur um 3,0 Prozent und 2,4 Prozent erhöhten..$^{40}$

Bei der Durchsetzung der Lohnerhöhungen profitierte die GTB von der Uneinigkeit im Arbeitgeberlager. 1964 waren zunächst alle Arbeitgeberverbände der Textilindustrie gegen eine weitere Wochenarbeitszeitverkürzung. Über sechs Verhandlungsrunden hinweg blieben die Arbeitgeber des Tarifgebiets Nordrhein bei ihrer Haltung. Die GTB führte in 25 Betrieben Urabstimmungen durch und begann mit Streiks. Fast gleichzeitig stimmte der Arbeitgeberverband in BadenWürttemberg der Wochenarbeitszeitverkürzung um eine Stunde zu, wenige Tage später auch die Arbeitgeber in Niedersachsen/Bremen und Hamburg/SchleswigHolstein. Nach nur wenigen Streiktagen wurde in Nordrhein der Grundurlaub um vier Tage auf 24 Werktage, also auf vier Wochen erhöht.

Die Abschlüsse in schwächeren Tarifgebieten konnten sowohl beim Urlaub als auch bei der Arbeitszeit dem Niveau der Vorreiter angeglichen werden. Dies führte dazu, dass sich die Arbeitgeberverbände bei Einkommen, Urlaub und Arbeitszeit von der Gewerkschaft getrieben fühlten. Die mangelnde Koordination und die Unfähigkeit, eine einheitliche Linie gegenüber der GTB aufzubauen und durchzuhalten, führten schon seit mehreren Jahren zu Diskussionen im Arbeitgeberlager.

Die von den Arbeitgebern finanzierte "Textilzeitung « hatte schon im März 1962 über die Mitgliederversammlung der Landesvereinigung der industriellen Arbeitgeberverbände berichtet und die Bekleidungstarifrunde 1961 unter dem Titel »Außenseiter wurden weich « analysiert: In völliger Verkennung der Notwendigkeit, solidarisch zu handeln, hätten einige Außenseiterfirmen, aber Mitgliedsunternehmen des Arbeitgeberverbandes, Haustarifverträge abgeschlossen, die die gewerkschaftlichen Wünsche weitgehend erfüllten. So habe man auf Verbandsebene Tarifverträgen zustimmen müssen, die wirtschaftlich nicht zu

38 Die juristische Niederlage der CTB führte dazu, dass die 1962 erzielte Mitgliedervorteilsregelung im Bausektor auch wieder aufgegeben werden musste.

39 BVG-Entscheidung vom 4.5.1971, 1 BvR 761/67.

40 CTB: Ceschäftsbericht 1963-1964 des Hauptvorstandes, S. 210. 
rechtfertigen seien. Die GTB antwortete stolz, man habe bewiesen, »daß auch in einem Industriezweig mit rund 85 Prozent weiblichen Beschäftigten die Mittel des Arbeitskampfes erfolgreich angewendet werden können. «"

Die Frage liegt nahe, warum die GTB nach dem eigenen »Godesberg « - dem Schwenk von der systemkritisch-konfrontativen Ausrichtung zur Sozialpartnerschaft (siehe Kapitel 3.2.4) - ihre harte Linie in der Tarifpolitik nicht änderte und die strukturelle Unterlegenheit der Arbeitgeberseite zur Durchsetzung von Forderungen oberhalb des branchenspezifischen verteilungsneutralen Spielraums nutzte. Die Ursachen lagen wohl auf beiden Seiten. Einerseits konnten sich die "Tauben« im Arbeitgeberlager nicht gegen die »Falken« durchsetzen, so dass den Gewerkschaftsforderungen grundsätzlich mit sturer Ablehnung begegnet wurde. Andererseits hatten in der GTB die »Reformer « zwar die Mehrheit, kontrollierten die Organisation aber nicht in Gänze. Diejenigen, die sich nicht mit den unteren Rangplätzen auf der gesamtwirtschaftlichen Lohnskala abfinden wollten, hatten in der Tarifpolitik weiterhin eine starke Stimme.

Außerdem herrschte Vollbeschäftigung, die Verbraucherpreise zogen an und die Erwartungshaltung der Beschäftigten war dementsprechend hoch. Die GTBFührung war zwar auf Sozialpartnerschaft ausgerichtet, gab aber dennoch nicht der Versuchung nach, die Mitgliederwünsche zu beschneiden. Die örtlichen Tarifkommissionen, in denen selbst Kleinbetriebe eine Stimme hatten, waren durch ihre Mitgliedernähe ein exakter Seismograph für die Ansprüche der Beschäftigten und die betrieblichen Funktionär:innen scheuten sich nicht, Auseinandersetzungen zu forcieren. Ein Beispiel hierfür ist die Tarifrunde 1964. Obwohl mit dem Textil-Arbeitgeberverband Nordrhein noch ein Einigungsversuch nach den Urabstimmungen verabredet war, traten die Beschäftigten in drei Wuppertaler Betrieben unmittelbar nach der Urabstimmung eigenständig in den Streik. Damit war die GTB gezwungen, die Verantwortung hierfür zu übernehmen und offiziell den Streik auszurufen. ${ }^{42}$

Die Uneinigkeit der Arbeitgeber angesichts des gewerkschaftlichen Drucks während der Tarifrunde hatte auch Folgen für Gesamttextil: 1964 trat Walter Bauer, Vorsitzender des Arbeitgeberkreises, nach der aus Arbeitgebersicht katastrophalen Tarifrunde von seinem Amt zurück. ${ }^{43}$ Es war ihm nicht gelungen, ein solidarisches Verhalten von Unternehmen und Regionalverbänden gegen die Arbeitszeitverkürzung zu organisieren, im Gegenteil: Gerade der Verband der Ba-

41 GTB: Ceschäftsbericht 1961-1962 des Hauptvorstandes, S. 64. Auch die anderen Informationen in diesem Absatz sind dieser Quelle entnommen.

42 Vgl. die Ausgaben vom 29.2.1964 der Westfälischen Rundschau, der Neuen Ruhr Zeitung und der Wuppertaler Nachrichten.

43 Cesamttextil: Ergebnisprotokoll der Sitzung des Arbeitgeberkreises vom 14. April 1964, BWA No2 93. 
den-Württembergischen Textilindustrie, dem er selbst angehörte, war der erste, der eine entsprechende Vereinbarung unterzeichnet hatte.

Insgesamt war die Lohnpolitik der GTB gegenüber der Textil- und der Bekleidungsbranche »radikaler" als die der IG Metall. Während die Metallgewerkschaft eine an der gesamtwirtschaftlichen Produktivität und Inflationsrate ausgerichtete Tarifpolitik verfolgte, hätte dies für die GTB die Zementierung der unteren Rangplätze in der bestehenden Lohnhierarchie bedeutet. Um den Abstand zu anderen Industriebereichen zu verringern, musste sie prozentual höhere Abschlüsse als die IG Metall durchsetzen.

Dies gelang ihr mehrfach, so dass sich der Abstand der textilen Monatslöhne zum gesamten Verarbeitenden Gewerbe zwischen 1957 und 1964 von 22 Prozent auf 17 Prozent verringerte, in der Bekleidungsindustrie von 32 Prozent auf 28 Prozent. ${ }^{44}$ Damit konnten die »Modernisierer « in der GTB auch unterstreichen, dass ihre Politik der Versachlichung nicht zur Folge hatte, dass sie weniger konsequent für Mitgliederinteressen streiten würden. Die tarifpolitischen Erfolge in der Bekleidungsindustrie schlugen sich in einem wachsenden Mitgliederstand nieder. Dieser erreichte im Jahr 1965 mit 90.300 Mitgliedern aus der Bekleidungsbranche einen Höchststand (siehe Tabelle 5 im Anhang).

Angesichts dieser Entwicklung verlief der Gewerkschaftstag im Herbst 1965, auf dem Karl Buschmann seine erste Bilanz als Vorsitzender vorlegte, äußerst ruhig. Was den verlorenen Streik um die Mitgliedervorteilsregelungen anging (siehe Kapitel 4.1.3), hoffte man zu diesem Zeitpunkt noch auf eine Korrektur durch höhere Gerichtsinstanzen. Ungeachtet der Auseinandersetzungen verwies Buschmann auf den »entscheidenden Beitrag«, den Gewerkschaften und Unternehmer zur demokratischen Ordnung zu leisten hätten, und führte aus:

»Die Art der Begegnung zwischen den Parteien im wirtschaftlichen Raume, und damit meine ich in erster Linie die Unternehmer und die Gewerkschaften, wird einen entscheidenden Einfluss auf die Qualität und Stabilität unserer Ordnung ausüben. Wir meinen nach wie vor, dass es höchste Zeit sei, die selbstverantwortliche Art der Begegnung nicht nur zu fordern und zu versprechen, sondern zu suchen und zu finden $\ll^{45}$

Die unbelehrbaren Arbeitgeber seien zwar noch in der Überzahl, aber es handele sich um einen langen Kampf, schließlich habe die Durchsetzung der 48-StundenWoche Jahrzehnte gedauert. Die von der GTB eingeleitete und längst überfälli-

44 Quelle: Verdiensterhebung des Statistischen Bundesamts (Destatis); eigene Berechnungen.

45 GTB: Protokoll des 9. Ordentlichen Gewerkschaftstages, 11.-15. Oktober 1965 in Stuttgart, S. 112. 
ge Entwicklung sei auch durch die westfälischen Arbeitgeber nicht aufzuhalten; neue Wege ebne man nicht durch Gerichte. ${ }^{46}$

Der Arbeitskampf um die Mitgliedervorteilsregelung im Frühjahr 1965 wurde zwar in den mündlichen Geschäftsberichten der GHV-Mitglieder angesprochen, spielte aber erstaunlicherweise in den Diskussionen auf dem Gewerkschaftstag keine Rolle. Weder die Frage, ob es klug gewesen sei, die Forderung per Streik gegen die von BBI bis BDA geschlossene Arbeitgeberfront durchzusetzen, noch die Frage nach der Richtigkeit der Durchsetzungsstrategie wurden gestellt. Auch über die zukünftige Ausrichtung der GTB wurde nicht diskutiert. Dies hatte zur Folge, dass der Gewerkschaftstag von 1965 in Anspielung auf den Slogan »Mach mal Pause « rückblickend als »Coca-Cola-Kongress « bezeichnet wurde. ${ }^{47}$

\subsubsection{Rationalisierungsschutz - der große Sprung?}

Bereits in den 1950er Jahren hatte Karl Buschmann auf die Folgen der Automatisierung von Produktionsanlagen in der Textilindustrie hingewiesen. Ganz im Sinne von Viktor Agartz' Konzept der expansiven Lohnpolitik (siehe Kapitel 3.1.6) forderte die GTB die Beschleunigung dieses Prozesses. In einer Entschließung des Gewerkschaftstages 1953 heißt es dazu:

»Die GTB ist für eine größtmögliche Steigerung der Produktivität. Deshalb bejaht und fordert sie auch eine sinnvolle Rationalisierung. Sie setzt dabei voraus und macht zur Bedingung, daß von bisher vielfach angewandten Methoden der rücksichtslosen Leistungssteigerung der menschlichen Arbeitskraft und der unvernünftigen Arbeitsplatzvergrößerung Abstand genommen wird. [...] Rationalisierungsmaßnahmen sollen die menschliche Arbeitskraft entlasten, die Produktion erhöhen und die Kosten senken. Eine solche Rationalisierung fördert die Kaufkraft und den Konsum und schafft damit neue Arbeitsmöglichkeiten. Die erhöhte Produktivität soll neben den niedrigen Preisen den Arbeitnehmern durch höhere Löhne zugutekommen. ${ }^{48}$

Im Konzept von Viktor Agartz waren Rationalisierung und Erhöhung der Massenkaufkraft sich gegenseitig bedingende Elemente des Fortschritts, die in ein Konzept der »Wirtschaftsdemokratie« eingebunden sein sollten. Die umfassende Mitwirkung der Gewerkschaft in einem solchen Modell war für die GTB je-

46 GTB: Protokoll des 9. Ordentlichen Gewerkschaftstages, 11.-15. Oktober 1965 in Stuttgart, S. 115.

47 Vgl. die Diskussionsbeiträge von Willi Linder und Hermann Verweyen auf dem Gewerkschaftstag von 1968, in: GTB: Protokoll des 10. Ordentlichen Gewerkschaftstages, 16.-20. September 1968 in Berlin, S. $38 f$.

48 GTB: Protokoll des 3. Ordentlichen Gewerkschaftstages, 16.-19. Juni 1953 in Düsseldorf, S. $356 \mathrm{f}$. 
doch utopisch. Sie kritisierte zwar steigende Belastungen, entwickelte aber kein Konzept, die Arbeitsgestaltung zu beeinflussen. Ein Ansatz, Einfluss auf die Formen der Rationalisierung nehmen zu wollen, war nicht erkennbar, vielmehr beschränkte sich die GTB-Politik darauf, die Belastungen lohnpolitisch und durch Verkürzung der Arbeitszeit zu kompensieren. Die Mitbestimmung der Betriebsräte beim Leistungslohn sollte eine grenzenlose Leistungssteigerung verhindern. ${ }^{49}$

In der zweiten Hälfte der 1950er Jahre wurde erkennbar, dass die Produktivitätsfortschritte durch die Automatisierung in der Textilindustrie tendenziell größer sein würden als der Anstieg des Textilverbrauchs. Buschmann sagte 1959 eine Abnahme der Beschäftigtenzahl voraus, fügte jedoch optimistisch hinzu, dass diese »sich bei allgemein guter Konjunkturentwicklung allerdings in engen Grenzen halten wird «. ${ }^{50}$ Dennoch sah er Handlungsbedarf:

»Wenn das Textilunternehmen Millionen für die Anschaffung von Maschinen ausgibt, daß man ihm dann auch zumuten kann, etwas für die zu tun, die von ihm auf die Straße gesetzt werden. $\aleph^{51}$

Diese kritische Betrachtungsweise verstärkte sich in den Folgejahren und mündete in der Forderung zum Abschluss eines »Rationalisierungsvertrags«. In dem Schreiben, mit dem im Jahr 1962 ein entsprechender Vertragsentwurf an Gesamttextil übermittelt wurde, betonte die GTB:

"So sehr von uns erkannt wird, daß die Rationalisierung in der Textilindustrie ein notwendiger Prozess ist, so energisch möchten wir auch unterstreichen, dass sie letzten Endes nur dann einen Sinn haben kann, wenn sie der Cemeinschaft dient und den Einzelnen vor sozialen Nachteilen schützt. ॥ $^{52}$

Die GTB forderte bessere Mitbestimmungsrechte für die Betriebsräte, Beteiligungsrechte der Gewerkschaft, den Vorrang von Umsetzungen vor Entlassungen und die Kostenübernahme für Umschulungsmaßnahmen sowie Abfindungen bei Entlassungen. Im März 1962 antwortete der Arbeitgeberverband:

»[...] in der Sache halten wir eine Ausweitung des Mitbestimmungsrechts für unnötig und unzweckmäßig [...]. Durch die beträchtlichen Lohnerhöhungen, Arbeitszeitverkürzungen, Urlaubsverlängerungen und ähnliches mehr, haben Sie mit

49 Vgl. Wassermann (1985): Arbeitsgestaltung als Cegenstand gewerkschaftlicher Politik, S. 177180.

50 CTB: Protokoll des 6. Ordentlichen Cewerkschaftstages, 24.-29. August 1959 in Nürnberg, S. 102.

51 GTB: Protokoll des 6. Ordentlichen Cewerkschaftstages, 24.-29. August 1959 in Nürnberg, S. 102.

52 Zit. nach: GTB (o.J.): Die sozialen Auswirkungen der Textilindustrie, S. 75. 
dazu beigetragen, die Textilindustrie zu Rationalisierungsmaßnahmen zu zwingen, [... dadurch] sind wir zur Zeit in unserer Wettbewerbsfähigkeit ernstlich bedroht. Schwerwiegende rechtliche Bedenken sowie die aufgeführten sozialpolitischen und allgemein wirtschaftlichen Erwägungen haben uns zu der Überzeugung gebracht, daß Ihr Vorschlag nicht im Interesse der deutschen Wirtschaft, der Textilindustrie, ihrer Arbeitnehmer und Arbeitgeber liegt. ${ }{ }^{53}$

Dieser schroffen Ablehnung folgte drei Monate später ein »Memorandum«, in dem Walter Bauer, der Vorsitzendes des Arbeitgeberkreises von Gesamttextil, weitgehende Vereinbarungen in Aussicht stellte. Neben der Gründung einer paritätischen Einrichtung, die Arbeitnehmer:innen im Falle von Entlassungen unterstützen sollte, könnten der Beitragseinzug durch Lohnbüros und die bezahlte Freistellung von Tarifkommissionsmitgliedern geregelt werden. Gesamttextil werde darüber hinaus seinen Mitgliedsunternehmen empfehlen,

»alles zu unterlassen was die Cewerkschaft, ihre volkswirtschaftliche Funktion, ihre Tätigkeit in den Betrieben sowie haupt- und ehrenamtliche Mitarbeiter diffamieren könnte ${ }^{54}$

Bauer stellte neben der Akzeptanz von Anerkennungsforderungen Zugeständnisse beim Schutz von Beschäftigten bei Rationalisierungsmaßnahmen in Aussicht und schlug vor, die Möglichkeiten der Annäherung im »kleinen Kreis« zu besprechen. Dies lehnte der GTB-Vorsitzende Werner Bock jedoch ab, weil Gesamttextil das in Aussicht gestellte Entgegenkommen mit Zugeständnissen bei den Lohnverhandlungen verband. Diese Verknüpfung von Rationalisierungsschutz und Lohnverzicht war für die GTB inakzeptabel, so dass die Einigungsversuche auf zentraler Ebene scheiterten.

In der Tarifrunde 1964, in der hauptsächlich für die Verkürzung der Wochenarbeitszeit gestritten wurde, setzte die westfälische Textiltarifkommission ihren Schwerpunkt auf die Vereinbarung eines sogenannten Rationalisierungstarifvertrags. Im westlichen Westfalen hatten Erneuerungen der Maschinenparks zu erheblichen Personalreduzierungen geführt; die überwiegend textile Struktur des Münsterlandes erschwerte Entlassenen den Wechsel in andere Branchen. Nachdem die Arbeitgeber zunächst starken Widerstand geleistet hatten, gelang im Februar 1964 die Vereinbarung des »Westfälischen Rationalisierungstarifvertrags «.

Die GTB feierte diesen Durchbruch als »Meilenstein auf dem langen und steinigen Weg der Verhandlungen ${ }^{55}$ obwohl das Ergebnis im Vergleich zu den

53 Zit. nach: CTB (o.J.): Die sozialen Auswirkungen der Textilindustrie, S. $76 \mathrm{f}$.

54 Bauer, Walter: Schreiben an Werner Bock vom 10. Juli 1962, AdsD 5/CTBA410250.

55 CTB: Ceschäftsbericht 1963-1964 des Hauptvorstandes, S. 230. 
Forderungen eher bescheiden ausfiel. I Pfennig der Stundenlohn-Erhöhung wurde in einen Fonds gezahlt, in den auch die Arbeitgeber je I Pfennig pro bezahlter Arbeitsstunde einzahlten. Aus Rationalisierungsgründen entlassene oder geringer bezahlte Arbeiter:innen über 50 Jahre sollten aus diesem Fonds »zwecks Hinderung von Altersrentenverlusten« zusätzliche Rentenversicherungsbeiträge erhalten. Die GTB musste dabei die Vertragsklausel hinnehmen,

»daß mit diesem Vertrag die Endlösung hinsichtlich der von der Cewerkschaft geforderten sSicherheit für Rationalisierung erreicht ist. Insbesondere haben sich die Forderungen auf Entlassungsgeld, Lohnausgleich bei Umsetzung sowie Vergütung für Wohnungswechsel und Umsetzung damit erledigt. ${ }^{56}$

In der Folge erreichte die GTB in den anderen Tarifgebieten der Textilindustrie weitere sogenannte Rationalisierungstarifverträge mit sehr unterschiedlichen Regelungen. Teilweise wurden ausschließlich die Kündigungsfristen verlängert oder es wurden als »Übergangshilfen« bezeichnete Abfindungen vereinbart. Im Tarifgebiet Südbayern gelang es, betriebsbedingte Kündigungen für Arbeitnehmer:innen ab 63 Jahren auszuschließen. ${ }^{57}$ Die Forderung nach einer umfassenderen Beteiligung und Absicherung von Beschäftigten bei technologischem Wandel blieb auf der tarifpolitischen Tagesordnung.

\subsubsection{8: Der Gewerkschaftstag zieht Bilanz}

Der Gewerkschaftstag im September 1968 war von juristischen Klagen der Arbeitgeber und ihrer Verbände und den beiden damit erwirkten empfindlichen Niederlagen der GTB vor dem Bundesarbeitsgericht (BAG) geprägt. Den Versuch, Mitgliedervorteilsregelungen gegen den Willen von Arbeitgebern durchzusetzen, hatte das höchste deutsche Arbeitsgericht als unrechtmäßig verurteilt (siehe Kapitel 4.1.3). Jetzt blieb nur noch die vage Hoffnung, die Entscheidung des Großen Senats des BAG vor dem Bundesverfassungsgericht angreifen zu können, die sich aber nicht erfüllen sollte.

Das Bundesarbeitsgericht versetzte der Tarifpolitik der GTB einen weiteren Schlag, indem es die 1955 erstmals durchgesetzte Effektivlohnklausel für rechtsunwirksam erklärte. Diese Tarifbestimmung garantierte, dass Tariferhöhungen nicht auf übertarifliche Lohnbestandteile angerechnet wurden. Das Urteil vom Februar 1968 hatte zur Folge, dass eine tarifvertraglich vereinbarte Entgelterhö-

56 Westfälischer Rationalisierungstarifvertrag, abgeschlossen zwischen dem Verband der Textilindustrie Westfalen, Münster, und der Cewerkschaft Textil-Bekleidung, Düsseldorf, 13. Februar 1964, AdsD 5/CTBA410255.

57 CTB: Ceschäftsbericht 1965-1967 des Hauptvorstandes, S. 297. 
hung keine Garantie mehr für eine tatsächliche Erhöhung des Lohnes oder Gehaltes der Beschäftigten war. ${ }^{58}$ Der Gewerkschaftstag war nun das Gremium, dem die Bilanz der sozialpartnerschaftlichen Ausrichtung der GTB vorzulegen war. Mit Kritik war zu rechnen, denn Buschmann stand, wie selbst die christlich-sozialen »Gesellschaftspolitischen Kommentare« resümierten, mit »leeren Händen $\ll$ da. ${ }^{59}$

In der GTB-Geschichte gab es keine längere Debatte zum Geschäftsbericht des Hauptvorstandes als auf diesem Kongress. Erst nach 53 Wortbeiträgen stimmten die Delegierten für den Schluss der Debatte. Im Fokus der Kritik standen die mangelnde Bereitschaft der Unternehmer und ihrer Verbände, die neue Ausrichtung der GTB zu respektieren, aber auch die fehlende Härte gegenüber den Arbeitgebern. Für den Delegierten Erich Lechtenberg aus Bielefeld waren entscheidende Erfolge der Politik der Versachlichung schlichtweg ausgeblieben. »Lieber Karl«, so spitzte er $\mathrm{zu}$, »Du bist für Deine Vorstöße in den Hintern getreten worden ${ }^{60} \mathrm{Er}$ warf die Frage auf, inwieweit die GTB sich mit dieser Politik selbst im Wege stehe.

Andere Delegierte fragten nach substanziellen Fortschritten und stellten die Logik der Anerkennungspolitik infrage, denn für Sozialpartnerschaft fehle der Partner. Wenn es darauf ankomme, verfielen die Unternehmer in die uralten Muster des Klassenkampfes. Fred Habicht aus Hannover stellte die Frage:

»Was muss denn noch alles passieren, um am Verhalten der Unternehmer zu erkennen, welchen Platz sie uns in dieser Cesellschaftsordnung einräumen wollen?«, und forderte: »[...] lösen wir uns aus der Ordnungsfunktion und werden wir wieder zu einem gestaltenden Unruhefaktor. « ${ }^{61}$

Für Robert Taubald aus Münchberg zeigten sich die Arbeitgeber auf keinem Feld zu substanziellen Zugeständnissen bereit. Es sei vergeblich, »Anerkennung« von den Arbeitgebern einzufordern:

»Wir sollten von der Einbildung abrücken, dass uns die Arbeitgeberseite auf diesem Wege auch nur von sich aus dazu einen kleinen Beitrag leisten wird. [...] So wie sie [diese Dinge] bis jetzt gelaufen sind, können sie nicht weiterlaufen. « ${ }^{62}$

58 BAG, 14.2.1968, Aktenzeichen 4 AZR 275/67.

59 Rüther (1968): Textilgewerkschaft zwischen Reformismus und Radikalismus, in: Gesellschaftspolitische Kommentare, Nr. 5 vom 1. März 1968, S. 59.

60 GTB: Protokoll des 10. Gewerkschaftstages, 16.-20. September 1968 in Berlin, S. 159.

61 GTB: Protokoll des 10. Gewerkschaftstages, 16.-20. September 1968 in Berlin, S. 125.

62 GTB: Protokoll des 10. Gewerkschaftstages, 16.-20. September 1968 in Berlin, S. 152 f. 
Willi Lindner aus Bremen stellte fest, nach fünf Jahren sei Bilanz zu ziehen: Habe man Verbesserungen des Verhältnisses der Arbeitgeber zu ihren Beschäftigten erreicht, wurden bei den gewerkschaftlichen Wirkungsmöglichkeiten wesentliche Fortschritte gemacht? "Nach Abgabe des Geschäftsberichtes kann es hier nur >Nein heißen«, schloss er. ${ }^{63}$

Aufseiten der »Reformer« warnte Wolfgang Stender, Delegierter aus Backnang, davor, »daß eine Methode, den Platz in unserer Gesellschaft zu erobern, auch darin liegen könnte, sich ausschließlich als Unruheherd zu bezeichnen«, und betonte die Ordnungsfunktion der Gewerkschaften. ${ }^{64}$ Mehrere Verteidiger der neuen Linie versuchten den Begriff der »Versachlichung « zu relativieren, bedeute er doch weder Blauäugigkeit im Hinblick auf Unternehmerinteressen noch Leisetreterei. Kennzeichnend dafür stellte Erich Meier aus Ebingen fest, Versachlichung heiße nichts weiter, als alle Probleme ohne ideologischen und emotionalen Ballast zu bearbeiten - es bedeute jedoch nicht, dass die Kapitalisten aufhören würden, sich wie Kapitalisten zu verhalten. Wer die Politik von Buschmann kritisiere, müsse eine Alternative auf den Tisch legen, sowohl sachlich als auch personell. ${ }^{65}$

Karl Buschmann verteidigte seine Linie. Er betonte, die Politik der Versachlichung und Anerkennung sei richtig gewesen und habe dazu geführt,

»daß wir einen ganzen Bereich gesellschaftspolitischer Fragen mit in unsere Forderungen aufgenommen haben, die in den anderen Cewerkschaften bei weitem noch nicht diskutiert worden sind. $«^{66}$

Es gehe um mehr als um Lohn, Arbeitszeit und Urlaub. Mit Blick auf die ausgebliebenen Erfolge verwies Buschmann auf die Geschichte: Man sei es gewohnt, Stück für Stück voranzukommen. Nur weil die GTB sich nicht auf ganzer Linie habe durchsetzen können, sei das kein Grund, die Politik für falsch zu halten. Er bezog sich auch auf Willy Brandt, der die Entspannungspolitik trotz der Besetzung der Tschechoslowakei wenige Wochen zuvor fortsetzen wollte. Außerdem betonte Buschmann:

»Niemand hat in der erweiterten Aufgabenstellung, die wir uns als Gewerkschaft gesetzt haben, von sich aus, durch seine eigene Verhaltensweise, sei es als Person

63 GTB: Protokoll des 10. Gewerkschaftstages, 16.-20. September 1968 in Berlin, S. 163.

64 GTB: Protokoll des 10. Gewerkschaftstages, 16.-20. September 1968 in Berlin, S. 147.

65 GTB: Protokoll des 10. Gewerkschaftstages, 16.-20. September 1968 in Berlin, S. $170 f f$.

66 GTB: Protokoll des 10. Gewerkschaftstages, 16.-20. September 1968 in Berlin, S. 182. 
oder sei es als Tarifkommission, sich irgendwie etwas auferlegen müssen, wodurch er in seiner Schwungkraft und seiner Aktivität gebremst worden wäre. ${ }^{67}$

Auch wenn die kritischen Stimmen in der Diskussion zur Linie der »Reformer überwogen, so konnten deren Kritiker keine klare inhaltliche oder personelle Alternative aufzeigen und wagten keine echte Kraftprobe. Die Wahlergebnisse der Führungsmannschaft waren zwar historisch schlecht, bestätigten aber dennoch das Übergewicht der sozialpartnerschaftlich orientierten GHV-Mitglieder. So zeigten die Ergebnisse zugleich, dass eine starke Minderheit der Delegierten Buschmanns Linie weiterhin kritisch gegenüberstand: Von 205 Stimmen erhielt er nur 138, also eine Zustimmung von 67,3 Prozent. Auch die anderen GHV-Mitglieder schnitten mit maximal 147 Stimmen historisch schlecht ab; Schlusslicht mit 129 Stimmen (62,9 Prozent) wurde der "Traditionalist « Martin Lange. ${ }^{68}$ Trotz der »leeren Hände« und der Welle der Kritik hatte sich die Mehrheit für die sozialpartnerschaftliche Linie als tragfähig erwiesen. Damit war spätestens nach diesem Gewerkschaftstag klar, dass ein Rollback zur Politik der 1950er Jahre auch bei den Vertreter:innen der Basis keine Mehrheit hatte.

\subsubsection{Die Rezession 1966/1967 - Ende des Wirtschaftswunders}

Ein weiteres Thema, das die Delegierten des 1968er-Gewerkschaftstages bewegte, war die Wirtschaftskrise von 1967. Nach mehr als fünfzehn Jahren Wirtschaftswachstum erlebte die Bundesrepublik 1967 die erste Rezession der Nachkriegszeit. Bis zu diesem Zeitpunkt hatte es keinerlei Konjunktursteuerung durch die Regierung gegeben, weil es der ehemalige Wirtschaftsminister und amtierende Bundeskanzler Ludwig Erhard grundsätzlich ablehnte, lenkend in die Wirtschaft einzugreifen. Einzig die Bundesbank nahm mit der Festsetzung des Leitzinses Einfluss auf das Wirtschaftsgeschehen. Angesichts der 1964er-Wachstumsrate des Bruttoinlandsprodukts von 6,7 Prozent erhöhte sie den Diskontsatz bis 1966 von 3,5 Prozent auf 5, 0 Prozent.

Die öffentliche Hand führte zunächst Steuersenkungen und danach ein rigoroses Sparprogramm durch; die Wirtschaft brach ein. Während die Gesamtwirtschaftsleistung 1967 um 0,3 Prozent zurückging, sanken die Umsätze bei Textil um 7,3 Prozent und bei Bekleidung sogar um 9,0 Prozent. In der Bekleidungsindustrie, die 1966 mit 408.000 Beschäftigen ihren absoluten Höchststand erreicht hatte, verloren im Folgejahr 35.000 Arbeitnehmer:innen ihren Arbeitsplatz (siehe Tabelle 9 im Anhang); die Textilindustrie baute 1967 sogar 48.000 Arbeitsplätze ab. Angesichts dieser Entwicklung beschloss die GTB, die Einkommens-

67 GTB: Protokoll des 10. Gewerkschaftstages, 16.-20. September 1968 in Berlin, S. 186.

68 GTB: Protokoll des 10. Gewerkschaftstages, 16.-20. September 1968 in Berlin, S. $192 \mathrm{ff}$. 
tarifverträge nicht zu kündigen und forderte die Arbeitgeber stattdessen im Juli 1967 auf, »unverzüglich in Verhandlungen über die soziale Sicherheit der Arbeitnehmer einzutreten ${ }^{69}{ }^{69}$

Die von CDU/CSU und FDP gebildete Bundesregierung war bereits 1966 gescheitert und durch die erste Große Koalition abgelöst worden. Deren sozialdemokratischer Wirtschaftsminister Karl Schiller hatte mit dem im Juni 1967 verabschiedeten Stabilitätsgesetz erstmals keynesianische Elemente in die deutsche Wirtschaftspolitik aufgenommen. Die »Konzertierte Aktion « wurde ins Leben gerufen, die Orientierungsdaten zum makroökonomisch relevanten Verhalten von Regierung, Gebietskörperschaften, Gewerkschaften und Bundesbank erarbeiten sollte. Ziel war es, einen hohen Beschäftigungsstand, Preisstabilität und ein angemessenes Wirtschaftswachstum zu erreichen. Schiller sprach vom »Tisch der gesellschaftlichen Vernunft«, an dem am 14. Februar 1967 die erste informelle Gesprächsrunde stattfand.

Die Gewerkschaften diskutierten die "Konzertierte Aktion" kritisch und wirkten erst nach der Klarstellung Schillers, keine Lohnleitlinien festzulegen, in dieser Runde mit. ${ }^{70}$ Dort wurde im Juni 1967 die Empfehlung verabschiedet, dass eine negative Lohnpolitik verhindert werden müsse, um die Kaufkraft nicht weiter zu schwächen. Diese von BDI und BDA mitgetragene politische Ausrichtung beeindruckte die Unternehmer im Lande jedoch wenig. Die GTB beklagte, dass die Betriebe in den Tarifverhandlungen unumwunden zugaben, »daß für sie jetzt der Zeitpunkt gegeben war, sich von angeblich überhöhten Löhnen oder sozialen Leistungen zu trennen ${ }^{7{ }^{71}}$

Die von der GTB geforderte Einwirkungspflicht, tarifwidriges Verhalten zu stoppen, verweigerten die Arbeitgeberverbände mit dem Argument, dies sei ihnen nicht erfolgversprechend möglich. ${ }^{72}$ Mit der als Kompensation für die Lohnpause erwarteten Verlängerung der Kündigungsfristen für Arbeitnehmer:innen konnten sich die Arbeitgeber ebenfalls nicht anfreunden. Nachdem die Einkommen je nach Tarifgebiet 18 bis 24 Monate lang stagnierten, kündigte die GTB schließlich die Lohn- und Gehaltstarifverträge zum 31. März 1968 und forderte eine Erhöhung der Tarifsätze um 5 Prozent. Angesichts der wieder angesprungenen Konjunktur konnten Verbesserungen in Höhe von 4,5 Prozent erreicht werden. Im Frühjahr 1969 setze die GTB weitere Tariferhöhungen von 6,5 bis 7 Prozent durch. Zusätzlich zu Strukturverbesserungen in den Lohngruppenschemata wurde 1970

69 GTB: Geschäftsbericht 1965-1967 des Hauptvorstandes, S. 301.

70 Karl Buschmann begrüßte die »Konzertierte Aktion« ausdrücklich und war sichtlich stolz darauf, der DGB-Delegation anzugehören.

71 GTB: Geschäftsbericht 1965-1967 des Hauptvorstandes, S. 302.

72 GTB: Geschäftsbericht 1965-1967 des Hauptvorstandes, S. 302. 
schließlich die 40-Stunden-Woche in der Textil- und der Bekleidungsindustrie erreicht.

Entgegen der Einschätzung der »Konzertierten Aktion« verdoppelte sich das Wirtschaftswachstum im Laufe des Jahres 1969 nahezu. Mit einer Zuwachsrate von 7,5 Prozent war es der stärkste Wachstumsschub der deutschen Wirtschaft seit 1959. Für die Eisen- und Stahlindustrie sowie die Metall- und Elektroindustrie hatte die IG Metall Mitte 1968 Tarifverträge abgeschlossen, die nicht vor Ende 1969 kündbar waren. Ausgehend von einem innerbetrieblichen Konflikt legten am 2. September 1969 die Arbeiter der Hoesch-Hüttenwerke in Dortmund die Arbeit nieder. Obwohl die geforderten 30 Pfennig Lohnerhöhung bereits einen Tag später zugesagt wurden, wurde dieser spontane Streik der Tropfen, der das Fass zum Überlaufen brachte. ${ }^{73}$ Rasch folgten weitere Belegschaften der Metallindustrie und anderer Branchen und forderten eine Beteiligung am außergewöhnlichen Produktionszuwachs. Insgesamt streikten im Herbst 1969 mindestens 1,4 Millionen Beschäftigte in der Stahl- und Metallindustrie, ohne dass ihre Gewerkschaft sie dazu aufgerufen hatte. Über 7 Millionen Beschäftigte kamen in den Genuss von zusätzlichen Einkommensverbesserungen.

Vierzehn Tage nach der ersten Arbeitsniederlegung streikten auch die Arbeiter:innen in der westfälischen »Jute-Spinnerei und -weberei«. Nachdem die GTB, die erst im Mai 1969 neue Tarifverträge vereinbart hatte, zunächst gezögert hatte, geriet sie nach weiteren spontanen Streiks unter Zugzwang. Am 10. Oktober forderte sie schließlich Nachverhandlungen, "um den Anschluss an diese Entwicklung nicht zu verlieren ${ }^{74}$ aber Gesamttextil verweigerte auf zentraler Ebene Tarifverbesserungen während laufender Tarifverträge. Die betriebliche Situation zwang die Arbeitgeber jedoch zu Zugeständnissen. Nachdem in Delmenhorst und Bremen 5.000 Beschäftigte in den Streik getreten waren, erhielten sie ab 1. November eine zusätzliche Erhöhung. Um weitere Arbeitsniederlegungen zu vermeiden und die Erhöhungen tariflich »einzufangen«, die nach Streiks oder Streikandrohungen betrieblich bereits gewährt worden waren, erklärte sich der westfälische Arbeitgeberverband zur Vereinbarung einer zusätzlichen Lohnerhöhung von 15 Pfennig pro Stunde ab 1. Januar 1970 bereit.

Die Bewegung des Jahres 1969 hatte den GTB-Hauptvorstand unvorbereitet getroffen. Noch einen Tag vor dem ersten »wilden« Streik in der Textilindustrie hatte Hermann Schumacher, der im GHV für Tarifpolitik verantwortlich war, dem Bundeswirtschaftsministerium gegenüber die Gefahr von spontanen Streiks in der Textil- und der Bekleidungsindustrie verneint. Auch intern sah Schumacher »keine Möglichkeit, uns mit den spontanen Arbeitsniederlegungen zu identi-

73 Der Spiegel (1969): Arbeitskampf-Wilde Woche, in: Ausgabe 38 vom 15.9.1969, S. 30-32.

74 GTB: Geschäftsbericht 1968-1970 des Hauptvorstandes, S. 342. 
fizieren «, wie er am 17. September 1969 in einem Rundschreiben ausführte. ${ }^{75}$ Trotz ihrer weiter vorhandenen Skepsis änderte die GTB-Führung diesen Kurs schnell, denn immerhin war neben der Stahl- und Metallindustrie und dem Öffentlichen Dienst auch die Textilindustrie in größerem Umfang von den Streiks betroffen. Mit den eingeforderten Verhandlungen setzte sie sich an die Spitze der Bewegung und erzielte dort, wo der Druck am stärksten war, auch Erfolge. Ihr Einsatz sollte belohnt werden: Mit 65.000 neu geworbenen Mitgliedern erreichte die GTB 1969 ihr bis dahin zweitbestes Jahresergebnis in der Mitgliederwerbung. ${ }^{76}$

\subsubsection{Der große Aufschwung}

Hatte die Rezession 1967 die Textil- und die Bekleidungsindustrie mit Umsatzund Beschäftigungseinbrüchen von fast 10 Prozent im Vergleich zum Vorjahr besonders getroffen, so erlebten sie 1969 einen Aufschwung, der sogar den industriellen Durchschnitt überflügelte. Die arbeitstägliche Produktion stieg in der Textilindustrie um 17,9 Prozent (Industriedurchschnitt 11,9 Prozent), in der Bekleidungsindustrie, die erst verzögert vom Aufschwung profitierte, um 11,1 Prozent. 1969 stiegen auch die Beschäftigtenzahlen in der Textil- und der Bekleidungsindustrie in der Bundesrepublik um zusammen 35.000 (siehe Tabelle 8 und 9 im Anhang). Der große Aufschwung überlagerte jedoch die Auswirkungen der sich abzeichnenden strukturellen Veränderungen.

$\mathrm{Zu}$ Beginn des Jahres 1970 kanalisierte die GTB die im Herbst zuvor wahrgenommene Stimmung mit der Forderung nach einer Einkommenserhöhung in Höhe von 14 Prozent wieder in eine gewerkschaftliche Tarifrunde. Die Arbeitgeberseite war offensichtlich von der Kampfbereitschaft der Beschäftigten beeindruckt und gestand noch während der Friedenspflicht Tarifverbesserungen von mindestens 10 Prozent zu. Aufgrund von Strukturverbesserungen in den Tarifverträgen erhöhten sich die Einkommen für einzelne Beschäftigtengruppen in der Bekleidungsindustrie um bis zu 14 Prozent und in der Textilindustrie sogar um bis zu 20 Prozent. ${ }^{77}$

Obwohl der "Sachverständigenrat zur Begutachtung der gesamtwirtschaftlichen Entwicklung« für 1971 eine Erhöhung des privaten Verbrauchs von 8 bis 9 Prozent prognostizierte, sah die GTB nicht nur optimistisch in die Zukunft. Aufgrund der großen Investitionssummen in der Textilindustrie, die sich auf eine noch stärker automatisierte Massenproduktion einstellte, würde es zu einer »Produktivitätsexplosion« kommen, die den Zuwachs der Nachfrage nach den

75 Gertschen (2013): Klassenfeinde-Branchenpartner?, S. 249.

76 GTB: Geschäftsbericht 1968-1970 des Hauptvorstandes, S. 224.

77 GTB: Geschäftsbericht 1968-1970 des Hauptvorstandes, S. 343 und 347. 
Produkten deutlich übersteigen würde. Man befürchtete eine »automatische Einsparung«von Arbeitsplätzen.

Auch auf die Außenhandelsentwicklung sah die GTB mit Sorge. Der Importüberschuss an Textilien und Bekleidung erreichte 1970 mit einem Zuwachs von 479 Millionen DM auf 2,8 Milliarden DM einen Höchststand. Noch lag der Schwerpunkt der Importüberschüsse bei Garnen und Maschenwaren, doch die Bekleidungsindustrie importierte zunehmend Fertigwaren. Die sogenannte passive Lohnveredelung, bei der die Vormaterialien aus der EG stammen mussten, während die Fertigung aber in den Ostblockstaaten ${ }^{78}$ erfolgte (siehe Kapitel 2.1.4), wuchs rasant an. Im Zuge der neuen Ostpolitik waren die Lieferkontingente für Textil- und Bekleidungserzeugnisse aus dem Ostblock von 1968 bis 1970 verdreifacht worden, für die passive Lohnveredlung stiegen sie um das Neunfache. ${ }^{79}$

\subsection{Die Kritische Akademie - Solitär der Tarifpolitik}

Die Maxime der GTB war, möglichst viel dessen, was das Arbeitsleben im weitesten Sinne betraf, durch Tarifverträge selbst zu regeln und nicht nach dem Staat zu rufen. Außerdem fühlte sich die Gewerkschaft über die Interessenvertretung der Arbeitnehmer:innen in materiellen Fragen hinaus dazu verpflichtet, sie durch politische Bildungsarbeit zu bewussten und urteilsfähigen Staatsbürger:innen zu erziehen - eine Lehre aus der Nazidiktatur. So gründete die GTB auf der finanziellen Basis, die durch den Tarifvertrag mit der Miederindustrie gelegt war (siehe Kapitel 4.1.2), die »Stiftung zur Förderung von Bildung und Erholung der Arbeitnehmer der Miederindustrie«, kurz »Miederstiftung« genannt. Diese führte $a b$ 1965 Seminare durch und bald entstand die Idee eines eigenen Hauses, das seine Arbeit 1977 als »Kritische Akademie« in Inzell/Oberbayern aufnahm.

\subsubsection{Lehren aus der Geschichte}

Das Politikverständnis des GTB-Vorsitzenden Karl Buschmann war von den Erfahrungen der Machtübernahme durch die Nationalsozialisten 1933 geprägt. Insbesondere die Tatsache, dass sich auch weite Teile der Arbeiterschaft den demokratiefeindlichen Kräften zugewendet hatten, erforderte Lehren aus der Geschichte. Hier lag Buschmann auf einer Linie mit dem ehemaligen Widerstandskämpfer und SPD-Bildungspolitiker Waldemar von Knoeringen, der ironisch und anerkennend zugleich »der rote Baron« genannt wurde. Von 1958 bis 1962 war Knoeringen Stellvertretender Vorsitzender der SPD und hielt die Eröffnungsrede

78 Vor allem in Bulgarien, der ČSSR, Jugoslawien, Polen, Rumänien und Ungarn.

79 GTB: Geschäftsbericht 1968-1970 des Hauptvorstandes, S. $379 \mathrm{ff}$. 
beim Godesberger Parteitag, auf dem das nach dem Tagungsort benannte Programm die Öffnung der SPD zur Volkspartei besiegelte.

Zur Sicherung eines kritischen demokratischen Bewusstseins wurde der politischen Bildungsarbeit ein zentraler Stellenwert zugeschrieben. Diese sollte nicht nur bildungsnahe Schichten der Gesellschaft erreichen, sondern auch die Arbeiterschaft und insbesondere Menschen, die unter Leistungsdruck kleinteilig zergliederte Arbeitsschritte ausführten.

Ein Jahr nach dem Tarifabschluss 1963 für die Miederindustrie, der eine regelmäßige Zahlung der Unternehmen an einen von der GTB gegründeten Verein vorsah, wurde die »Stiftung zur Förderung von Bildung und Erholung der Arbeitnehmer der Miederindustrie " gegründet, die umgehend ihre Bildungsarbeit aufnahm. Die Seminare fanden in Hotels und Gaststätten statt, aber bald wurde die Schaffung eines Bildungs- und Erholungshauses für die Beschäftigten dieser Branche in Erwägung gezogen. Die seit 1965 durchgeführten Kurse wurden nach der traditionellen Methode "Vortrag und Diskussion« durchgeführt. Zunehmend stellten sich die Verantwortlichen der Stiftung die Frage, wie effektiv die Lehrmethoden waren und welcher "Bildungserfolg" sich insbesondere bei den Akkordarbeiterinnen feststellen ließ. Beeinflusst wurde diese Diskussion auch durch die gesellschaftlichen Umwälzungsprozesse, die von den Studentenprotesten 1968 ausgingen. ${ }^{80}$

\subsubsection{Die Kritische Akademie wird Wirklichkeit}

Unter der Leitung von Waldemar von Knoeringen wurde 1970 eine Denkschrift für ein Modell einer Kritischen Akademie veröffentlicht, in die sowohl die Erfahrungen von GTB, Miederstiftung und Georg-von-Vollmar-Akademie, einer von Knoeringen gegründeten Bildungseinrichtung, als auch die Erkenntnisse von Wissenschaftler:innen und Reformideen zur Bildungsmethodik einflossen. Die Denkschrift beschrieb nicht nur den theoretischen Ansatz bis hin zur Organisation einer Bildungseinrichtung neuen Stils, sondern ging bis zur baulichen Gestaltung. Zentrales Anliegen des Konzeptes war die Schaffung einer Bildungsstätte, die ihre Hauptaufgabe nicht in der Vermittlung von Fakten und politischem Wissen sieht, sondern vom Selbstverständnis getragen ist, »daß der einzelne Teilnehmer sich selbst sowohl als Ausgangspunkt wie auch als Gegenstand politischen Handelns begreift«. Demokratie sollte nicht als etwas Fertiges, sondern als ständige Aufgabe gesehen werden. ${ }^{81}$

80 Vgl. Stiftung zur Förderung von Bildung und Erholung der Arbeitnehmer der Miederindustrie (1970): Denkschrift. Die Kritische Akademie. Ein Modell.

81 Georg-von-Vollmar-Akademie (1971): Der Kochel-Brief II, S. 26. 
Parallel $\mathrm{zu}$ den theoretischen Überlegungen hatte die Stiftung 1970 ein Grundstück in Inzell erworben und entschied Ende des Jahres, an diesem Ort eine solche Kritische Akademie zu errichten. Im Sinne Knoeringens sollten dabei die Erkenntnisse kritischer Didaktik in ein den Bedürfnissen gemäßes Gebäude »übersetzt« werden. ${ }^{82}$ Nach Auffassung der Initiatoren konnten die neuen Unterrichtsmethoden nur erfolgreich verwirklicht werden, wenn dafür auch die baulichen Voraussetzungen geschaffen würden, die den Anforderungen einer kritischen Didaktik genügen. ${ }^{83}$

Damit wurde aus dem Arbeitstitel die endgültige Bezeichnung der Bildungseinrichtung. Im Januar 1977 hielt Bundeskanzler Helmut Schmidt die Festrede zur Eröffnung der Kritischen Akademie, des bis dahin ersten Erwachsenenbildungshauses, das von Bildungsexperten und Architekten gemeinsam entwickelt wurde. In seiner Rede unterstrich Schmidt seine Dankbarkeit »für die Beharrlichkeit, mit der unsere Gewerkschaften einen ihrer Verantwortung sich bewusst bleibenden Gebrauch von ihrem autonomen Handlungsspielraum gemacht haben«. Er zeigte sich beeindruckt »hinsichtlich des ständigen Drängens auf Veränderung, auf Erneuerung, auf Reform, und dankbar bin ich für den Mut und die Stetigkeit, mit der dabei auch gegen Egoismus und Ellenbogenideologie gekämpft wird «. ${ }^{84}$

In den nächsten Jahren konnten die Beschäftigten der Miederindustrie in der Kritischen Akademie zahlreiche Bildungsangebote mit gesellschaftspolitischen Inhalten in Anspruch nehmen. Die Schulungen fanden hauptsächlich in Form von Wochenseminaren, aber auch als Wochenendseminare statt. Die Kritische Akademie hatte eine medizinische Badeabteilung, so dass Kuren für die durch kurze Arbeitstakte und einseitige körperliche Beanspruchung belasteten Beschäftigten angeboten werden konnten. In belegungsschwachen Zeiten, z. B. im Sommer oder in Wochen mit Feiertagen, konnten Arbeitnehmer:innen hier zu Sonderkonditionen mit ihren Familien Urlaub machen. Für viele Niedrigverdienende wurde dadurch überhaupt erst eine Urlaubsreise möglich.

Planung und Errichtung der Kritischen Akademie fielen in die Zeit der großen Auslandsverlagerung der Bekleidungsproduktion. Die Beschäftigtenzahl der Unternehmen, die unter den Tarifvertrag für die Miederindustrie fielen, sank rapide, so dass die finanziellen Mittel auf dieser Grundlage nicht mehr ausreichten, um die Einrichtung zu finanzieren. Durch Gastbelegungen der GTB und externer Organisationen und Unternehmen wurde die wirtschaftliche Existenz weiterhin gesichert. Die Angebote für die laut Tarifvertrag Anspruchsberechtigten blieben nicht nur erhalten, sondern wurden ausgebaut. Jedes Jahr war über ein Drittel der Berechtigten Gast in der Kritischen Akademie.

82 Naffin (2002): Kritische Akademie Inzell, S. 71.

83 Naffin (2002): Kritische Akademie Inzell, S. 75.

84 Naffin (2002): Kritische Akademie Inzell, S. 52. 
Manche konzeptionellen Überlegungen veralteten durch neue Ansprüche. Hatte man beim Bau noch bewusst auf Doppelzimmer gesetzt, um den Gemeinschaftscharakter zu fördern, so wurden bald Einzelzimmer Standard und von den Gästen erwartet. Dem wurde 1995 durch einen Anbau mit zwanzig zusätzlichen Einzelzimmer-Appartements Rechnung getragen.

Nach der Integration der GTB in die IG Metall im Jahr 1998 (siehe Kapitel 8.1) blieb die Kritische Akademie eine Einrichtung der eigenverantwortlichen Miederstiftung - nun mit enger Anbindung an die IG Metall, aber weitgehender formeller und tatsächlicher Autonomie, da die Einrichtung keine Mittel von der Gewerkschaft benötigte oder erhielt. Durch die Tarifvereinbarung »Bildung im Tarifvertrag« (BiT) für die Textil- und die Bekleidungsindustrie und eine spätere Vereinbarung für den Bereich Textile Dienste erhielt die Kritische Akademie neue Aufgaben aufgrund von Tarifverträgen, die jedoch bei weitem nicht ausreichten, um ihre wirtschaftliche Grundlage zu sichern.

Unter Wilfried Hess, dem Leiter der Akademie und Geschäftsführer der Stiftung, wurden attraktive Bildungsangebote entwickelt, z. B. im Bereich der PCNutzung in einer Zeit, als diese noch längst nicht in allen Betriebsratsbüros üblich war, oder auf dem Gebiet des Individualarbeitsrechts, auf dem es bisher keine Angebote der IG Metall gegeben hatte. Nicht nur diese Bildungsangebote stießen auf großes Interesse, seit 2013 organisiert die Stiftung zudem in enger Kooperation mit der Bezirksleitung Bayern die regionale Bildungsarbeit für Betriebsräte sowie Jugend- und Ausbildungsvertretungen des IG Metall-Bezirks.

Die erwirtschafteten Mittel wurden in die inhaltliche Weiterentwicklung, moderne Seminarräume sowie Ausbau und Modernisierung der Einrichtung investiert, deren stürmische Entwicklung auch anhand der Umsatzzahlen deutlich wird. Die jährlichen Einnahmen erhöhten sich von rund 3 Millionen D-Mark im Jahr 1995 auf 11,5 Millionen Euro im Jahr 2019. Innerhalb von zwanzig Jahren konnten 30 Millionen Euro an eigenen Mitteln in den Ausbau investiert werden. Den veränderten Schwerpunkten trägt die Stiftung, die heute "Stiftung Bildung, Erholung und Gesundheitshilfe« heißt, auch mit ihrer Namensänderung Rechnung.

Die Kritische Akademie bleibt ein Beispiel für die Innovationskraft bei Tarifverträgen, auch wenn der Tarifvertrag für die Miederindustrie heute nur noch eine untergeordnete Bedeutung hat - und auch keine Nachahmer gefunden hat.

\subsection{Neue Herausforderungen erfordern eine neue Akzentsetzung}

Lange bevor der Begriff Globalisierung in den allgemeinen Sprachgebrauch überging, bekam die Textilindustrie deren Auswirkungen zu spüren. Schon unmittelbar nach Gründung der Bundesrepublik übertrafen die Textilimporte die 
exporte. In den 1960er Jahren stiegen diese von 12 auf 20 Prozent des Umsatzes der bundesdeutschen Textil- und Bekleidungsindustrie, 1975 stieg diese Marke auf 32 Prozent. Insbesondere Hongkong, Macau, Taiwan und Südkorea bauten ihre Textil- und Bekleidungsproduktion stark aus. Diese Staaten mit autoritären Regierungen, restriktiven Bestimmungen hinsichtlich gewerkschaftlicher Organisation, niedrigen Löhnen und geringen Sozialstandards konzentrierten ihre wirtschaftliche Entwicklung in den 1970er Jahren stark auf die Bekleidungs- und Textilindustrie, wobei die Produkte ausschließlich für den Export in die Industriestaaten gefertigt wurden.

Die GTB betrachtete diese Entwicklung von Beginn an kritisch und thematisierte die Gefahr für die heimischen Arbeitsplätze seit Mitte der 1960er Jahre verstärkt öffentlich. Die deutschen Hersteller konnten im zunehmend schärfer werdenden Wettbewerb mit den Niedriglohn-Anbietern nur durch technische und betriebswirtschaftliche Kreativität konkurrieren. Allerdings sind diesem Wettbewerb im Bekleidungsgewerbe aufgrund der nach wie vor handwerklichen Fertigungsweise Grenzen gesetzt.

Zuvor war die GTB in wirtschaftspolitischen Fragen kein Gesprächspartner für die Arbeitgeberverbände, im Bundeswirtschaftsministerium wurde sie allenfalls am sogenannten Katzentisch geduldet. Diese Konstellation änderte sich ab Ende 1966 mit Karl Schiller als erstem sozialdemokratischem Wirtschaftsminister (siehe Kapitel 4.3.2). Die Arbeitgeberverbände verloren ihren exklusiven $\mathrm{Zu}$ gang, ihre Interessenlage in der Handelspolitik differenzierte sich aus, die GTB avancierte zur Sprecherin der Textil- und der Bekleidungsbranche. Grundsätzlich gesprächs- und kooperationsbereit, änderte die Bundesregierung ihre liberale Handelspolitik zunächst nicht und lenkte erst nach heftiger öffentlicher Gegenwehr in Teilbereichen ein.

Die GTB musste ihre Tarifpolitik also unter schwieriger werdenden Wettbewerbsbedingungen gestalten. Hinzu kam die Herausforderung hoher Preissteigerungsraten, der dadurch gesteigerte Erwartungsdruck bei den Mitgliedern und die 1974 einsetzende Ölpreiskrise, die den Arbeitsplatzabbau beschleunigte.

\subsubsection{Die Branchenpolitik gewinnt an Bedeutung}

Auf dem Gewerkschaftstag 1968 machte sich Karl Buschmann neben tarif- und gesellschaftspolitischen Aspekten für ein neues Aufgabenfeld stark: die Wirtschaftspolitik und hier insbesondere die Handelspolitik. Die zunehmenden Textil- und Bekleidungsimporte setzten die Branchen unter Druck. Gesamttextil hatte schon in den 1950er Jahren Maßnahmen zum Schutz der heimischen Industrie gefordert. Die GTB stand diesem Ansatz seinerzeit kritisch gegenüber und verwies auf die unternehmerischen Aufgaben zur Erhaltung konkurrenzfähiger Produkte. 
Im Hinblick auf den internationalen Handel setzte die GTB auf die gewerkschaftliche Entwicklung in den asiatischen Produktionsländern. In Japan war es gelungen, Gewerkschaften aufzubauen und die Arbeitsbedingungen zu verbessern. Eine solche Entwicklung versuchte man in allen Ländern zu fördern und dadurch die Konkurrenz auf sozialem Gebiet einzuschränken. Gute Arbeitsbedingungen sollten den Handel fairer machen und gleichzeitig die regionalen Märkte stärken, so dass sich die neuen Produktionsländer nicht nur auf den Export konzentrierten. Jedoch würde dieser Prozess eine gewisse Zeit benötigen, weshalb sich die GTB schon Ende der 1950er Jahre dem Bundeswirtschaftsministerium gegenüber zumindest für einen begrenzten Zeitraum ebenfalls für eine restriktive Einfuhrpolitik aussprach. ${ }^{85}$

Zehn Jahre später wurde die Positionierung auch nach außen deutlicher. Die GTB sah die Textilindustrie der Konkurrenz durch ständig steigende Einfuhren ausgesetzt, was zunehmend Arbeitsplätze in Deutschland gefährdete. Ihr Vorsitzender Buschmann stellte im Jahr 1968 die Frage, inwieweit unter unterschiedlichsten Sozial- und Arbeitsbedingungen produzierte Waren fair miteinander konkurrieren könnten. Er kritisierte, dass solche Produkte völlig frei auf dem Weltmarkt gehandelt würden. Zielländer der Textilherstellung in Niedriglohnländern seien ausschließlich die entwickelten Industrieländer in Europa, hier insbesondere die Bundesrepublik Deutschland und die USA. Setze sich dieser Prozess unreguliert fort, seien in den Industrieländern Arbeitsplätze gefährdet, ohne dass die breite Masse in den Entwicklungsländern nachhaltig von der Bekleidungs-Monostruktur profitieren würde.

Für die Unternehmerverbände war die GTB bis Mitte der 1960er Jahre kein Partner, mit dem man auf Augenhöhe Branchenprobleme diskutierte oder gar gemeinsame Strategien zur Beeinflussung der Politik entwickelte. Die GTB als Interessengruppe auf nationaler Ebene mit einzubeziehen berührte offensichtlich zu sehr das Selbstverständnis der Unternehmer als »Herren« der Textil- und der Bekleidungswirtschaft. Auf europäischer Ebene hingegen, wo die Distanz zu den betrieblichen und tariflichen Auseinandersetzungen größer war, wurde die GTB von Comitextil, dem Zusammenschluss der europäischen textilen Industrieverbände, regelmäßig hinzugezogen und nahm so Einfluss auf die Handelspolitik der EWG. ${ }^{86}$

In der Bundesrepublik hatten die Arbeitgeber unter der Kanzlerschaft von Konrad Adenauer und Ludwig Erhard einen guten Zugang zum Bundeswirtschaftsminister, auch wenn sie mit ihren Anliegen nicht besonders erfolgreich waren. Die Distanz zur GTB speiste sich aus der Befürchtung, dass die Gewerk-

85 Vgl. die GTB-Aktennotiz über ein Gespräch von Karl Buschmann mit Dr. Töpfer, dem Textilreferenten des BMWi, am 12. November 1958, AdsD 5/GTBA100140.

86 Gertschen (2013): Klassenfeinde-Branchenpartner?, S. 208. 
schaft tarifpolitische Konzessionen einfordern würde, wenn sie sich gemeinsam mit den Arbeitgeberverbänden für einen stärkeren Schutz der Textilindustrie gegen Importe einsetzte. Nach dem Regierungswechsel 1966 und der Bildung der ersten Großen Koalition hatte mit Karl Schiller ein Sozialdemokrat den Chefsessel im Wirtschaftsministerium inne. Dies war zugleich das Ende der »alten Welt«, in der sich der Wirtschaftsminister die Redekonzepte für seine Treffen mit der GTB von Gesamttextil vorbereiten ließ.

Die GTB-Spitze hatte sich nach 1963 von der grundsätzlichen Skepsis oder gar Gegnerschaft zu den Unternehmern verabschiedet (siehe Kapitel 3.2.4). Im 1968 vorgelegten Geschäftsbericht erkannte sie ausdrücklich die unternehmerischen Erfolge an. Gerade die Textilindustrie sei hoch leistungsfähig, wurde betont, könne sich aber nur unter fairen Wettbewerbsbedingungen entwickeln. Die Textilgewerkschaft forderte

»keinen Naturschutzpark zur Überdeckung eventueller unternehmerischer Fehlleistungen. Sie erwartet aber von den zuständigen und für alle Bürger verantwortlichen politischen Gremien und staatlichen Stellen eine Wirtschafts-, Finanz- und Handelspolitik, die mit Nachdruck im inländischen wie im ausländischen Wirtschaftsbereich für gleiche Wettbewerbsmöglichkeiten für alle Industriezweige eintritt. Den verständlichen Wünschen sogenannter Entwicklungsländer, ihre Importe an Maschinen und anderen industriellen Erzeugnissen durch Lebensmittel und Textilerzeugnisse bezahlen zu wollen, muss durch eine ausgewogene Wirtschafts-, Finanz- und Handelspolitik begegnet werden. ${ }^{87}$

Gesamtwirtschaftlich hatte sich die Bundesrepublik zu einem Exportland entwickelt. Daher hatten die meisten Unternehmen und die Bundesregierung kein Interesse an Handelsbeschränkungen. Grundsätzlich erkannten diese Akteure, dass man auch Entwicklungsländern kompensierende Exporte zugestehen müsse, und da boten sich Textil- und Bekleidungswaren an. Außerdem ist der internationale Textilhandel auch vor dem Hintergrund des Kalten Krieges zu betrachten, denn die Förderung der wirtschaftlichen Entwicklung sollte die Resistenz gegenüber kommunistischen Bestrebungen und Bewegungen stärken - angesichts der Arbeitsbedingungen in den asiatischen »Sweatshops« kein wirklich erfolgversprechendes Konzept. Dennoch fand die GTB mit ihrer Vorstellung eines fairen Welthandels selbst in der Gewerkschaftsfamilie kaum Resonanz. Deutsche Maschinen mit asiatischen Textilien $\mathrm{zu}$ bezahlen, mit einer so ausgerichteten Wirtschaftspolitik hatte die IG Metall zu dieser Zeit keine größeren Probleme.

Mitte der 1960er Jahre begann die GTB, die steigenden Textil-BekleidungsImporte als strukturelle Gefahr für Arbeitsplätze in Deutschland stärker in den

87 CTB: Geschäftsbericht 1965-1967 des Hauptvorstandes, S. 25. 
Fokus ihrer Politik zu rücken. In der 1966 einsetzenden Rezession startete sie eine Kampagne, in deren Rahmen sie auf Betriebsversammlungen ihre Position zum Schutz der Arbeitsplätze deutlich machte. In einem Schreiben an Vizekanzler Willy Brandt und Wirtschaftsminister Karl Schiller forderte sie dringend faire Handelsbedingungen und den Schutz der heimischen Branchen.

Dass die GTB jetzt nicht nur die Arbeitsbedingungen im Blick hatte, sondern die Branchenentwicklung zu einem großen Thema machte, entsprach zwar dem Anliegen der meisten Textilunternehmer, war aber vielen von ihnen trotzdem nicht geheuer. Einerseits sprach Gesamttextil-Präsident Nicolaus H. Schilling von völliger Übereinstimmung; andererseits war das Misstrauen tief, die GTB werde sich Erfolge bei der wirtschaftspolitischen Unterstützung an den eigenen Hut heften und danach womöglich tarifpolitische Forderungen geltend machen. ${ }^{88}$ Ein Großteil der Unternehmer witterte hier keine Chance, sondern einen Hinterhalt. ${ }^{89}$ Doch langsam setzte im Unternehmerlager ein Umdenken ein und man fragte sich, ob ein gemeinsames Vorgehen die Einflussnahme auf die Import- und Wirtschaftspolitik vergrößern könne. Die Unternehmer planten, eine Reihe von Betriebsversammlungen wohlwollend zu begleiten - doch als der GTB-Vorsitzende Karl Buschmann 1967 auf einer Betriebsversammlung zum Auftakt dieser Versammlungsreihe auch vorsichtig die Tarifpolitik ansprach, beendete Gesamttextil jegliche Kooperation, bevor sie überhaupt Formen angenommen hatte. ${ }^{90}$

\subsubsection{Koordinatenwechsel in der Politik: Die sozialliberale Koalition}

Der exklusive Zugang der Arbeitgeberverbände zum Wirtschaftsministerium fand mit dem Sturz von Bundeskanzler Ludwig Erhard sein Ende. Mit Karl Schiller brachte ein sozialdemokratischer Wirtschaftsminister keynesianische Globalsteuerungsinstrumente in die Wirtschaftspolitik ein. Wie Karl Buschmann setzte der »Godesberger « Schiller auf die Vorstellung einer partnerschaftlichen Zusammenarbeit auf sachlicher Ebene selbst bei gegensätzlichen Interessen. Ein Schritt zu einer solchen Politik war die »Konzertierte Aktion«, die Schiller ins Leben rief. Buschmann, Mitglied der entsprechenden DGB-Delegation, hatte jetzt einen direkten Draht ins Ministerium und wurde im November 1967 auch vom Minister empfangen. ${ }^{91}$ Die GTB war dorthin vorgedrungen, wo gesamtwirtschaftliche Entscheidungen getroffen wurden.

Jedoch verfolgte Schiller bei allen Freundlichkeiten gegenüber der GTB weiter die handelspolitische Liberalisierung. Bundesaußenminister Willy Brandt sah im

\footnotetext{
88 Gesamttextil: Protokoll Hauptausschusssitzung vom 9. Juni 1967, BWA No2 57.

89 Gertschen (2013): Klassenfeinde-Branchenpartner?, S. 239.

90 Gertschen (2013): Klassenfeinde-Branchenpartner?, S. 221.

91 Gertschen (2013): Klassenfeinde-Branchenpartner?, S. 214.
} 
Außenhandel ein Mittel, um politische Entspannung mit wirtschaftlichen Vorteilen für die Staaten jenseits des Eisernen Vorhangs zu verbinden. Insbesondere in der Bekleidungsproduktion gab es in allen Ländern das Grund-Knowhow und entsprechende Produktionsstätten, eine Ausweitung war rasch und ohne allzu große Investitionen möglich. Als Gastredner auf dem Gewerkschaftstag 1968 vertrat Schiller diese Position dann auch kaum verklausuliert. Buschmann schlug anschließend gerade wegen der bestehenden Meinungsverschiedenheiten eine »kleine konzertierte Aktion « auf Branchenebene vor.

Das Wirtschaftsministerium richtete tatsächlich einen »Arbeitskreis Textilwirtschaft« als institutionelle Gesprächsrunde ein. Nachdem geklärt war, dass sozialpolitische Fragen nicht Gegenstand dieser Runde sein würden, beteiligten sich auch Gesamttextil und BBI an den Gesprächen..$^{92}$ Dieser Vorgang ist kennzeichnend für den Rollenwechsel der GTB, die bei der Bundesregierung eine branchenpolitische Gesprächsrunde erreichte, an der auch die Arbeitgebervertreter teilnahmen und die zum Initiator für branchenpolitische Aktivitäten wurde. Alle Branchenbeteiligten, also Gesamttextil, BBI und GTB, machten die Importe zum Kernthema und sprachen sich für Höchstgrenzen aus, wenn extreme Unterschiede bei Lohnkosten und Sozialbedingungen vorlagen. Das Bundesministerium für Wirtschaft hatte damit wenig im Sinn und präferierte die Idee, die Industrie stärker an den Importlizenzen zu beteiligen, um ihr über eine »Mischkalkulation« $\mathrm{zu}$ ermöglichen, günstigere Preise anbieten zu können. ${ }^{93}$

Hatten viele Unternehmer auf ein "sozialdemokratische Intermezzo" im Wirtschaftsministerium gehofft, so sahen sie sich nach der Bundestagswahl 1969 einer Koalition von SPD und FDP mit einem SPD-Bundeskanzler gegenüber. Dieser politische Umbruch und das erkennbare Reformklima samt einer von der Regierung geplanten Mitbestimmungsinitiative versetzte insbesondere die Unternehmer in der Textil- und der Bekleidungsbranche in Unruhe. Für viele schienen sich Abgründe zu öffnen und in der Vorstellungswelt mancher Unternehmerverbände stand der Sozialismus unmittelbar vor der Tür. ${ }^{94}$

Das Wirtschaftsministerium blieb in der Hand von Karl Schiller und die Politik der neuen Bundesregierung wich nicht grundsätzlich vom Kurs des stärkeren Freihandels ab, im Gegenteil: Die neue Ostpolitik wurde durch die Aufstockung der Kontingente für die "passive Lohnveredelung « flankiert. Diese Form der Produktionsverlagerung in Länder mit niedrigen Löhnen wurde von den großen Bekleidungsunternehmen genutzt, doch die Mehrheit der »Kleinen « innerhalb der BBI sorgte dafür, dass sich ihr Verband gegen diese Politik wandte. Noch sah sich

92 Certschen (2013): Klassenfeinde-Branchenpartner?, S. 237.

93 Gertschen (2013): Klassenfeinde-Branchenpartner?, S. 239.

94 So bildete der starke Verband der Nordwestdeutschen Textilindustrie eine Art Kampffonds zur Verteidigung des freien Unternehmertums. 
die Mehrheit der Unternehmer im BBI auf einer Linie mit Gesamttextil. Die Bundesregierung dagegen förderte die Ausweitung der Importmöglichkeiten als Mittel zur Preisdämpfung und Entspannung des Arbeitsmarktes, befand man sich doch mitten im Wirtschaftsboom der Jahre 1969/1970.

Die Positionen von Gesamttextil und BBI waren nicht ohne innere Widersprüche. Bekleidungsunternehmen ließen schon seit Beginn der 1960er Jahre im Ausland fertigen - Seidensticker-Hemden kamen aus Hongkong, Trenchcoats des Marktführers F.W. Brinkmann wurden in Polen genäht. Auch Textilunternehmen sahen sich nach ausländischen Produktionsstätten um oder importierten einfache Produkte und Vorstufenerzeugnisse. Unzweideutig war von allen Branchenakteuren nur die Haltung der GTB, deren Anliegen die Verteidigung der inländischen Arbeitsplätze gegen die aus ihrer Sicht unfair produzierende Konkurrenz war. Im Ostblock waren es die niedrigen Lohnkosten, die auch durch politisch festgesetzte Wechselkurse erreicht wurden. In den asiatischen Textilexportländern gab es kaum freie gewerkschaftliche Betätigungsmöglichkeiten, vielfach herrschten unmenschliche Arbeitsbedingungen, Kinderarbeit und selbst Zwangsarbeit. Zudem verschärfte die Konkurrenz aus der EG, insbesondere aus Italien, den Druck auf die bundesdeutschen Hersteller.

Aus dieser Konstellation, ihrer klaren Linie und ihrer Nähe zur SPD, die nun den Kanzler stellte, erwuchs der GTB die tonangebende Rolle in der Branchenpolitik der nächsten Jahre. Trotz grundsätzlicher Loyalität zur sozialliberalen Regierung setzte sie diese branchenpolitisch erheblich unter Druck und erzielte eine erstaunliche Wirkung.

\subsubsection{Stürmische Zeiten - Beschäftigung unter Druck}

Bis 1973 profitierten die Textil- und die Bekleidungsindustrie von der wachsenden Wirtschaft. Preisbereinigt stieg das Bruttoinlandsprodukt von 1970 bis $1973 \mathrm{im}$ Durchschnitt um jährlich 4 Prozent; die Ausgaben für den privaten Konsum stiegen jährlich sogar um fast 5 Prozent. ${ }^{95}$ Bundesregierung und Bundesbank sahen die gesamtwirtschaftliche Stabilität gefährdet, so dass die Bundesbank das Geld knapp und teuer machte, was insbesondere die Mittelständler traf. Die Bundesregierung versprach sich darüber hinaus von mehr Importen eine preisdämpfende Wirkung. Im Rahmen eines »Stabilitätsprogramms« beschloss sie im Mai 1973, die Importmöglichkeiten aus den Ostblockstaaten und Südostasien um 900 Millionen DM zu erhöhen, wovon 700 Millionen DM auf Textil- und Bekleidungsimporte entfielen.

95 Statistisches Bundesamt (Destatis) (2019): Volkswirtschaftliche Gesamtrechnungen. Inlandsproduktberechnung. Lange Reihen ab 1970, S. 120. 
Das Wirtschaftsministerium war nach der Bundestagswahl 1972 an die FDP gefallen und Wirtschaftsminister Hans Friderichs ging auf die GTB-Proteste nicht ein. Auf dem Umweg über Brüssel - die Maßnahmen mussten von der EWG genehmigt werden - gelang es der GTB, die Erhöhung des textilen Importvolumen auf 400 Millionen DM zu drücken. ${ }^{96}$ Dennoch verdoppelte sich der Importüberschuss bei Textilien von 1970 bis 1972. Einen wesentlichen Beitrag dazu leistete die »Containerisierung « des internationalen Handels. Wurde die Fracht zuvor einzeln als Stückgut und seefest verpackt, erleichterten, beschleunigten und verbilligten nun genormte Container, die auf Straße wie auf See transportiert werden konnten, Verpackung und Transport von Massenwaren. ${ }^{97}$

Noch bevor die arabischen Länder nach dem Jom-Kippur-Krieg 1973 die erste Ölpreiskrise auslösten, was zu einer weltweiten Rezession führte, zeigten sich schon Krisenanzeichen bei Textil und Bekleidung. Überdurchschnittliche Produktivitätssteigerungen führten $1973 \mathrm{zu}$ einem Rückgang der Arbeitsplätze in der Textilindustrie um 5,3 Prozent, in der Bekleidungsindustrie verringerte sich die Beschäftigung um 3,3 Prozent - der mit Ausnahme des Rezessionsjahres 1967 höchste Wert in der Nachkriegsgeschichte der Branche. ${ }^{98}$

Die bundesdeutsche Wirtschaft rutschte 1974 in eine Rezession, die 1975 in einem Rückgang des Bruttoinlandsproduktes um 0,9 Prozent mündete und das Ende der Vollbeschäftigung für die nächsten Jahrzehnte bringen sollte. 1976 erholte sich die Gesamtwirtschaft mit einem Wachstum von 4,9 Prozent deutlich. ${ }^{99}$ In der Textil- und der Bekleidungsindustrie führten die Strukturprobleme jedoch $\mathrm{zu}$ einem anhaltenden Beschäftigungsrückgang. Von 1973 bis 1977 gingen über 180.000 Arbeitsplätze verloren, was einem Rückgang um rund 25 Prozent bei Textil und 29 Prozent bei Bekleidung entsprach. ${ }^{100}$

Ausschlaggebend waren mehrere Gründe. So hatte sich die Textilindustrie auf Massenproduktion eingerichtet; die in großen Mengen produzierten Standardartikel wurden nun zunehmend importiert. Die unterausgelasteten Kapazitäten der deutschen Unternehmen erschwerten die Refinanzierung der teuren Maschinenparks, was in Verbindung mit der Hochzinspolitik zu vielen Unternehmenszusammenbrüchen führte. Durch die Krise 1974/1975 änderte sich das Konsumverhalten; angesichts von drohender Arbeitslosigkeit waren die hohen Steigerungsraten des privaten Verbrauchs passé. Außerdem erreichte der Kulturwandel bei Bekleidung, der mit der 1968er Bewegung eingesetzt hatte, jetzt auch

96 GTB: Geschäftsbericht 1971-1973 des Hauptvorstandes, S. 95.

97 Vgl. Preuß (2007): Eine Kiste erobert die Welt.

98 GTB: Geschäftsbericht 1971-1973 des Hauptvorstandes, S. 104 f.

99 Statistisches Bundesamt (Destatis) (2019): Volkswirtschaftliche Gesamtrechnungen. Inlandsproduktberechnung. Lange Reihen ab 1970, S. 120.

100 Statistisches Bundesamt (2008): Fachserie 4, Reihe 4.1.1. 
die Mitte der Gesellschaft. Klassische Anzüge und Kostüme waren immer weniger gefragt, die ausländische Konkurrenz wurde immer größer.

\subsubsection{Soziale Freunde, liberale Feinde: Die GTB mobilisiert die Branchen}

Seit 1969 stellte die SPD als mit den Gewerkschaften traditionell verbundene Partei den Bundeskanzler. Schon mit ihrem Regierungseintritt 1966 hatten sich die Verhältnisse gewandelt. Gewerkschaftliche Forderungen wurden Wirklichkeit. Mit einem modernisierten Berufsbildungsrecht und der Lohnfortzahlung für Arbeiter:innen im Krankheitsfall setzte die neue Regierungskoalition sozialpolitische Meilensteine. Das 1972 in Kraft getretene neue Betriebsverfassungsgesetz erleichterte den gewerkschaftlichen Zugang zu den Betrieben und damit die Gründung von Betriebsräten. Insofern sah die GTB

»die Hoffnung, daß die seit Jahren überfälligen gesellschaftspolitischen Reformen jetzt endlich verwirklicht und eine arbeitnehmerfreundlichere Politik einsetzen werde. [...] Die Hoffnung hat sich [...] als tragfähig erwiesen.«101

In der Tat waren die flexible Altersgrenze ab 63 Jahren für den Renteneintritt, die Öffnung der Rentenversicherung für Hausfrauen, eine Krankenversicherungsreform, mit der auch Vorsorgeuntersuchungen Kassenleistungen wurden, ein höheres Kindergeld und bessere Wohngeldbestimmungen in Kraft getreten.

Zwar fand die GTB im Bundeswirtschaftsministerium offene Türen vor, aber keine Bereitschaft, den liberalen Textil- und Bekleidungshandel einzuschränken. Ganz im Gegenteil hatte man dort aus politischen Gründen und zur Dämpfung der Preissteigerung höhere Textilimporte ermöglicht. Dies führte bei Buschmann trotz der Zustimmung zur Regierungspolitik im Hinblick auf sozialpolitische Maßnahmen zu schärferen Tönen, wo es um die Branchenpolitik ging. Wenn die Ostpolitik einseitig zulasten der Beschäftigten in der Textil- und Bekleidungsindustrie gehe, dann habe die Loyalität gegenüber dieser Politik und der Bundesregierung ihre Grenzen. ${ }^{102}$ Immer dringlicher wurde darauf hingewiesen, dass die Mitglieder der Gewerkschaft auf Kampfmaßnahmen drängten. Dies wurde in Regierungskreisen durchaus ernst genommen, zählte man doch Buschmann "mit seiner im Grunde sehr einsichtigen Gewerkschaft« zu den Gemäßigten unter den Gewerkschaftsführern. ${ }^{103}$

101 GTB: Geschäftsbericht 1971-1973 des Hauptvorstandes, S. 51.

102 Gertschen (2013): Klassenfeinde-Branchenpartner?, S. 244.

103 BMWi-Vermerk über das Gespräch Ehmke-Buschmann von 8. Dezember 1970, zit. nach Gertschen (2013): Klassenfeinde-Branchenpartner?, S. 244. 
Im zweiten Halbjahr 1973 schaltete die GTB von aggressiver Rhetorik auf konkrete Maßnahmen um. Die Textilkonjunktur trübte sich weiter ein; abgesehen von den Personalreduzierungen befanden sich Ende des Jahres 80.000 Beschäftigte in Kurzarbeit. ${ }^{104}$ Neben den steigenden Importen trafen die Konjunkturdämpfungsmaßnahmen die mittelständische Branche besonders hart. Auf regionalen Kundgebungen forderte die GTB ein Ende dieser restriktiven Wirtschaftspolitik und rief schließlich zu einem »Marsch auf Bonn« auf. Lange genug hatte die Gewerkschaft die Lippen gespitzt; in Bonn zeigte man sich nun erschrocken, dass auch gepfiffen wurde. Neben einer Lockerung der Anti-Inflations-Stabilitätspolitik forderte die GTB eine aktive Branchenpolitik. Außerdem solle die Regierung ein Szenario entwickeln, um die Frage zu beantworten, welche Kapazitäten im Textil- und Bekleidungssektor mittel- und langfristig notwendig und erwünscht seien. Vor diesem Hintergrund sei auch die »Theorie der weltweiten Arbeitsteilung « zu überprüfen und zu überarbeiten. ${ }^{105}$

Die Bundesregierung reagierte. Bereits im Vorfeld der Demonstration beschloss sie, die Erhöhung der Einfuhren aus den Ostblockländern für 1974 zurückzunehmen und die Importquoten aus Asien zu senken. Nach der Kundgebung mit 12.000 Teilnehmer:innen am 13. Dezember 1973 in Bonn beschloss das Bundeskabinett, die Finanzierungsmöglichkeiten für kleine und mittelgroße Unternehmen im Allgemeinen und speziell für die Textil-, Schuh- und Bauwirtschaft auszuweiten. ${ }^{106}$

Die GTB war eine öffentliche Konfrontation mit der Bundesregierung eingegangen, aber in differenzierter Form. Zwar sah man auch Transparente wie "Willy, denk daran, bald sind Wahlen«, aber den Hauptstrom des Zorns konnte man gegen FDP-Wirtschaftsminister Hans Friderichs lenken. Helmut Schmidt als für die Konjunkturpolitik verantwortlicher Finanzminister blieb weitgehend von Vorwürfen verschont. Die Demonstration war durchaus im Interesse von Gesamttextil, auch wenn man sich mit der öffentlichen Unterstützung zurückhielt. So musste der Arbeitgeberverband mit ansehen, wie die GTB in der Öffentlichkeit erfolgreich zur Vertreterin der Branche aufstieg. Diese Sicht unterstrich der frisch gekürte Bundeskanzler Helmut Schmidt im Herbst 1974, als er in seinem Grußwort auf dem GTB-Gewerkschaftstag Karl Buschmann als den »wichtigste[n] und bedeutendste[n] Sprecher der Textil- und Bekleidungsindustrie « bezeichnete. ${ }^{107}$

Die Proteste der GTB 1973 sollten kein einmaliges Aufbäumen sein, im Gegenteil: In den 1970er und 1980er Jahren machte die GTB Aktivitäten für sichere

104 textil-bekleidung, Ausgabe 12/1973, S. 3.

105 textil-bekleidung, Ausgabe 1/1974, S. 12.

106 Gertschen (2013): Klassenfeinde-Branchenpartner?, S. 291.

107 GTB: Protokoll des 12. Ordentlichen Gewerkschaftstages, 3.-8. November 1974 in München, S. 14 . 
Arbeitsplätze zu einem zentralen Aktionsfeld. Sie entwickelte Konzepte, wie sich soziale Fragen in Handelsverträge aufnehmen ließen. Freihandel könne nur mit Ländern vereinbart werden, die die Kernarbeitsnormen der Internationalen Arbeitsorganisation ILO ratifiziert hätten und auch anwendeten. Dies betrifft insbesondere die Punkte Vereinigungsfreiheit, also die Möglichkeit zur freien gewerkschaftlichen Betätigung, und das Verbot von Kinder- und Zwangsarbeit.

\subsubsection{Kämpferische Lohnpolitik zum Auftakt der 1970er Jahre}

Die spontanen Streiks von 1969 (siehe Kapitel 4.1.7) hatten Wirkungen für die Folgejahre und die auf Sozialpartnerschaft ausgerichtete GTB fiel nicht gerade durch tarifpolitische Leisetreterei auf. Auch unter dem Druck, der insbesondere aus dem Tarifbezirk Nordrhein der Textilindustrie kam, setzte sie 1970 bis $1973 \mathrm{Ta}-$ rifabschlüsse durch, die oberhalb des Industriedurchschnitts lagen. So erhöhten sich die Stundenlöhne in der Textilindustrie in diesem Zeitraum um 51 Prozent, in der Gesamtindustrie um 47 Prozent. Die Effektivlöhne in der Textilindustrie stiegen allein 1970 um 13,5 Prozent, während sie im gesamten Verarbeitenden Gewerbe um 11,8 Prozent stiegen. ${ }^{108}$

In der Bekleidungsindustrie gelang es 1970 erstmals seit 1962, einen Tarifabschluss auf Bundesebene zu erreichen, doch schon im Folgejahr scheiterten diese zentralen Verhandlungen wieder. Nach Urabstimmungen und Streiks, die schwerpunktmäßig in Westfalen organisiert wurden, erreichte die GTB 1971 neben einer Lohnerhöhung von 9 Prozent die Verlängerung des Jahresurlaubs um vier Tage. Trotz der Auseinandersetzungen in dieser Tarifrunde wurden die Verhandlungen für die Bekleidungsindustrie auch in der Folge auf Bundesebene weitergeführt. In der Textilindustrie wurde 1971 zwar nicht gestreikt, aber der Durchbruch zu neuen Tarifverträgen ebenfalls erst nach Urabstimmungen erreicht.

Um die Auswirkungen des Verbots der Effektivlohnklausel (siehe Kapitel 4.1.6) zu begrenzen, forderte die GTB 1971 auch strukturelle Tarifverbesserungen. Die Tariflöhne sollten »vorweg«, also im Vorfeld der eigentlichen Lohnerhöhung angehoben werden. Diese Anhebung, so das Konzept, sollte mit übertariflichen Lohnbestandteilen verrechenbar, also für die Betriebe kostenneutral sein. Dadurch sollte der Spielraum der Unternehmen, übertarifliche Löhne mit Tariferhöhungen $\mathrm{zu}$ verrechnen, verkleinert werden. Hier konnte sich die Gewerkschaft jedoch noch nicht durchsetzen.

1973 folgte eine dramatische Tarifrunde. Die Inflationsrate war deutlich im Steigen begriffen, was sich jedoch erst im Laufe des Frühjahrs nach Beschluss der

108 Statistisches Bundesamt (Destatis) (2017): Verdiensterhebung im Produzierenden Gewerbe, Handel, Kredit- und Versicherungsgewerbe ab 1950. 
Tarifforderungen in vollem Umfang zeigte. ${ }^{109}$ Die Tarifforderungen wurden $\mathrm{zu}$ Anfang des Jahres beschlossen, die Tarifverträge dann zu Ende April gekündigt. Angestrebt waren 60 Pfennig für alle Lohngruppen, was einer durchschnittlichen Erhöhung von 11 Prozent entsprach. Angesichts der Hochkonjunktur und der Preissteigerungsrate wurden im Frühjahr 1973 in anderen Branchen bereits Tarifabschlüsse in dieser Höhe erzielt, aber die Tarifverhandlungen für die Textilbranche scheiterten im Pilotbezirk Nordrhein Anfang Mai. Wieder führte die GTB Urabstimmungen durch und unternahm vor dem beschlossenen Streikbeginn einen letzten Einigungsversuch.

Weil das letzte Angebot der Arbeitgeber von 59 Pfennig abgelehnt worden war, mussten diese zur Abwendung der bereits festgelegten Streiks die Tarifforderung in voller Höhe, also 60 Pfennig für alle Tarifgruppen, erfüllen. Zusätzlich wurden eine Erhöhung des Urlaubsgelds um 60 DM und eine tarifliche Jahressonderzahlung zu Weihnachten in Höhe von 25 Prozent eines Monatseinkommens vereinbart (siehe Kapitel 4.3.6). Auch die Bekleidungsindustrie akzeptierte die volle Erfüllung der 60-Pfennig-Forderung und neben dieser Entgelterhöhung konnte auch hier ein Einstieg in das 13. Monatseinkommen vereinbart werden.

Während eine Branchenkrise in der Textil- und der Bekleidungsindustrie schon 1973 spürbar war, setzte 1974 - ausgelöst durch den Ölpreisschock - eine allgemeine Wirtschaftskrise ein. Die Tarifpolitik der Folgejahre musste sich in einer "scharfen Krise« bewähren, die - wie der entsprechende Geschäftsbericht ausführt - die Branchen besonders hart traf. Während die Gesamtzahl der Arbeitsplätze in der Bundesrepublik von 1974 bis 1977 um 3,0 Prozent abnahm, betrug der Beschäftigungsabbau in den Branchen Textil und Bekleidung 26,5 Prozent mehr als ein Viertel der Arbeitsplätze gingen verloren. Trotzdem setzte die GTB in diesen vier Jahren Tariferhöhungen von insgesamt 33,9 Prozent bei Textil und 33,1 Prozent bei Bekleidung durch. Dadurch stiegen die Realeinkommen in diesen Branchen um durchschnittlich 2,8 Prozent jährlich, in der Gesamtwirtschaft wurden durchschnittlich 2,9 Prozent erreicht. Nach den kampfbestimmten Tarifrunden 1970 bis 1973 wurden diese Ergebnisse in der Textilindustrie ohne größere Kampfmaßnahmen erzielt.

In der Bekleidungsindustrie zeigten sich die Verhandlungen auf Bundesebene fragil. So verweigerten die Arbeitgeber der Bekleidungsindustrie Nordrhein 1975 die Anerkennung des auf Bundesebene erzielten Ergebnisses, die unterfränkischen Arbeitgeber scherten 1976 aus, wurden aber schließlich doch auf das Bundesergebnis verpflichtet. In Nordrhein bedurfte es eines Streiks, aber am zweiten Streiktag lenkte der Arbeitgeberverband ein, was die von ihm vertretenen Unter-

109 Der Verbraucherpreisindex stieg 1972 um 5,4 Prozent und 1973 um 7,1 Prozent; vgl. Statistisches Bundesamt (Destatis) (2021): Preise. Verbraucherpreisindizes für Deutschland. Lange Reihen ab 1948, JD-Index. 
nehmen zusätzliche 0,2 Prozent Lohnerhöhung im Vergleich zum Bundesergebnis kostete. Diese Ergebnisse zeigen, dass die Einkommensentwicklung in der Tarifpolitik nach wie vor an erster Stelle stand. Besondere beschäftigungssichernde Tarifforderungen formulierte die GTB in dieser Zeit nicht. Die aktive Lohnpolitik wurde auch als stabilisierend für den privaten Konsum mit der daraus folgenden beschäftigungssichernden Wirkung begründet.

Aus heutiger Sicht ist diese aktive, teilweise aggressive Lohnpolitik nicht leicht verständlich. Ein wichtiger Faktor waren die ungewohnt hohen Preissteigerungsraten, die insbesondere niedrige Einkommensgruppen trafen. Trotz aller Tariferfolge lagen die Verdienste in der Textil- und der Bekleidungsindustrie im Vergleich mit allen industriellen Verdiensten auf den hinteren Rängen. Im gesamtindustriellen Vergleich erreichten die Entgelte im Bereich Textil und Bekleidung bei 42 Industriezweigen maximal Position 34. 1973 lag die Differenz zum industriellen Durchschnitt bei den Bruttomonatsverdiensten bei Arbeiter:innen in der Textilindustrie im Vergleich zum gesamten Verarbeitendem Gewerbe bei 126 DM monatlich (16,6 Prozent), bei den Arbeiter:innen in der Bekleidungsindustrie bei 217 DM (28,6 Prozent). Trotz prozentual ungefähr gleich hoher Abschlüsse vergrößerte sich die Differenz bis 1980 bei Textil auf 226 DM, bei Bekleidung auf 352 DM monatlich. ${ }^{110}$

Dass die Unternehmen durch die Tariferhöhungen nicht grundsätzlich überfordert wurden, zeigt ein Blick auf die Lohnquoten. Der Anteil der Löhne und Lohnnebenkosten am Umsatz sank in der Textilindustrie leicht von 23,4 Prozent im Jahr 1970 auf 23,1 Prozent im Jahr 1980. Bei Bekleidung fiel die Lohnquote im gleichen Zeitraum von 24,6 Prozent auf 23,0 Prozent. ${ }^{111}$ Trotz der hohen Arbeitsplatzverluste herrschte in der GTB-Mitgliedschaft also keine Verzichtsstimmung. Angesichts der Sozial- und Arbeitsbedingungen in den neuen Produktionsländern in Fernost gab man sich nicht der Illusion hin, dass Arbeitsplätze durch Lohnverzicht zu erhalten seien.

Ein von Gesamttextil für Oktober 1973 erstellter internationaler Lohnvergleich wies für die Textilindustrie in der Bundesrepublik Deutschland Gesamtlohnkosten (einschließlich Sozialabgaben, Urlaubs- und Feiertagsentgelte, sowie Krankheitskosten) pro Stunde von 10,06 DM aus, für Hongkong betrug dieser Satz 1,45 DM. ${ }^{112}$ Der Schutz der Arbeitsplätze vor dieser Konkurrenz wurde auf dem Feld der Handelspolitik bearbeitet.

Der lohnpolitische Erfolg der GTB in Zeiten des "rheinischen Kapitalismus" wurde nicht zuletzt durch den die Arbeitgeberverbände einschließenden Konsens

\footnotetext{
110 Statistisches Bundesamt (Destatis) (2017): Verdiensterhebung im Produzierenden Gewerbe, Handel, Kredit- und Versicherungsgewerbe ab 1950.

111 Berechnungen der CTB; vgl. die entsprechenden Ceschäftsberichte des Hauptvorstandes.

112 Cesamttextil: Lohnkostenvergleich pro Arbeiterstunde, BWA V12 303.
} 
erleichtert, dass die Einkommensentwicklung in allen Branchen zumindest im Großen und Ganzen mit der gesamtwirtschaftlichen Entwicklung Schritt halten müsse.

\subsubsection{Neue tarifpolitische Felder werden bestellt}

Nachdem die GTB in den 1960er Jahren ein tarifliches Urlaubsgeld durchgesetzt hatte, erreichte sie in der kampfbestimmten Tarifrunde 1973 einen Einstieg in die Absicherung des bislang von vielen Firmen ohne rechtliche Verpflichtung gezahlten Weihnachtsgeldes. Nun wurden zunächst 25 Prozent eines Monatsentgelts als verbindliche Jahressonderzahlung in der Vorweihnachtszeit gezahlt. Zuvor gab es in den Textil- und Bekleidungsunternehmen die unterschiedlichsten Regelungen, die jedoch stets "freiwillig « und ohne einen Rechtsanspruch für die Zukunft zu begründen gezahlt wurden - oder manchmal auch nicht. Außerdem wurden die Arbeitgeber zur Zahlung sogenannter vermögenswirksamer Leistungen, einer staatlich begünstigten Sparförderung, verpflichtet. Für die Bekleidungsindustrie gelang es, ein neues Lohntarifschema zu vereinbaren. Nachdem die GTB mit der Forderung, die Tarifsätze vor Erhöhungen kostenneutral anzuheben und dadurch übertarifliche Leistungen abzusichern, 1971 gescheitert war, gelang ihr das in Folgejahren mehrfach.

Neben diesen zur Lohnpolitik zählenden monetären Tarifleistungen wurden Konzepte für eine menschlichere Arbeitswelt entwickelt (siehe Kapitel 6.3.1). Dazu zählte der Ansatz, Lohnzuschläge - sei es für Mehrarbeit, Schicht- oder Wochenendarbeit - anstatt in Geld auch in Form von bezahlter Freizeit zu gewähren. Ein weiterer tariflicher Erfolg gelang 1974: Der »Tarifvertrag zum Schutz älterer Arbeitnehmer" schützte über 55-Jährige grundsätzlich vor betriebsbedingten Kündigungen und sicherte ihren Verdienst bei Akkord- und Prämienlohn.

Am Ende dieses für die Bekleidungsindustrie beschäftigungspolitisch katastrophalen Jahrzehnts gelang gerade hier ein großer Schritt in der qualitativen Tarifpolitik. In der Tarifrunde 1979 wurde durch den Abschluss eines BundesManteltarifvertrags für die Bekleidungsindustrie der 18-jährige tariflose Zustand auf diesem Feld beendet. Mit dieser Vereinbarung wurde die Mitbestimmung der Betriebsräte bei der menschengerechten Arbeitsplatzgestaltung ausgeweitet, Mindestzuschläge für Beschäftigte im Leistungslohn garantiert und weitere Verbesserungen erzielt (siehe Kapitel 6.3.1).

Die Durchsetzung des Tarifvertrags 1979 verband die GTB geschickt mit der populären Forderung nach vollen sechs Wochen Jahresurlaub für alle. Insbesondere um die Verhandlungskommission in diesem Punkt zu unterstützen, legten 28.000 Beschäftigte am entscheidenden Verhandlungstag die Arbeit nieder - mit Erfolg: Der neue Tarifabschluss sicherte eine sofortige Urlaubsverlängerung um zwei Tage; ab 1982 war der Urlaubsanspruch von sechs Wochen im Jahr mit einer 
nochmaligen Verlängerung unabhängig von Betriebszugehörigkeit und Lebensalter erreicht. Damit war die Bekleidungsindustrie beim Jahresurlaub, wie bereits Anfang der 1960er Jahre, erneut führend.

\subsection{Reformen im DGB und in der GTB}

Eine Grundvoraussetzung für die gewerkschaftliche Durchsetzungsfähigkeit ist finanzielle Stärke - nicht nur im Hinblick auf die Möglichkeit, die Mitglieder bei Arbeitskämpfen zu unterstützen. Stärker noch als heute spielten schnelle Erreichbarkeit, persönliche Präsenz und räumliche Nähe zu den Gewerkschaftsbüros zu der Zeit eine Rolle, als deutlich weniger Kommunikationsmittel und digitale Möglichkeiten der Informationsbeschaffung zur Verfügung standen. Um diese Ziele zu gewährleisten, bedurfte es einer Organisation, die nicht zu viele Ressourcen für die Verwaltung verbrauchte, um eine optimale personelle Ausstattung für die Betreuung vor Ort zu garantieren und genügend finanzielle Mittel für die Bildungsarbeit verwenden zu können.

In der unmittelbaren Nachkriegszeit erfreuten sich die Gewerkschaften eines großen Zulaufs, doch nach 1952 schrumpfte die Mitgliederzahl tendenziell. Bis 1960 sank der Organisationsgrad der GTB von 55 Prozent auf 38 Prozent. Die gewerkschaftspolitischen Maßnahmen der neuen GTB-Führung gegen diese Entwicklung sind in Kapitel 3.2 beschrieben, doch die »Reformer « wollten auch nach innen wirken. Sie hatten den Anspruch, auch die innere Organisation zu modernisieren und zu professionalisieren, um die Gewerkschaft finanziell zu stärken und effektiver auszurichten.

Dazu gehörte auch die Frage der Arbeitsteilung zwischen den in den 1960er Jahren sechzehn Mitgliedsgewerkschaften und dem DGB als übergeordnetem Dachverband: Wer sollte welche Aufgaben wahrnehmen? Die Struktur des DGB mit seinen selbstständigen Gewerkschaften war maßgeblich von den alliierten Besatzungsmächten geprägt worden. Die angestrebte deutsche Gewerkschaftseinheit fiel jedoch der deutschen Teilung zum Opfer; nach der Berlin-Blockade 1948 war der gesamtdeutsche Ansatz gestorben. Danach entwickelte sich der ursprünglich angestrebte starke Bund der westdeutschen Gewerkschaften immer differenzierter, nicht zuletzt wegen der unterschiedlichen Voraussetzungen für die Organisierung der Beschäftigten, stärker werdenden Einzelgewerkschaftsinteressen und unterschiedlicher politischer Ausrichtungen. 


\subsubsection{Strukturelle Schwierigkeiten}

Im Vergleich $\mathrm{zu}$ anderen Industriegewerkschaften hatte die GTB strukturelle Nachteile. Die Textil- und die Bekleidungsindustrie waren im Gegensatz zu den führenden Industriebranchen durch eine Klein- und Mittelbetriebsstruktur geprägt. Der hohe Anteil von Frauen, deren Rolle in der Arbeitswelt der ersten Nachkriegsjahrzehnte nur als "vorübergehend« definiert wurde, erleichterte die gewerkschaftliche Organisation nicht (siehe Kapitel 5.2). Hinzu kamen unterhalb des Industriedurchschnitts liegende Löhne, was entsprechend geringe Gewerkschaftsbeiträge zur Folge hatte. Gewerkschaften in Branchen mit vielen Großbetrieben und anderer Beschäftigtenstruktur hatten deutlich bessere Voraussetzungen, was bereits in den 1950er Jahren zu großen Unterschieden bei Beiträgen und Leistungen geführt hatte. Heinz Vietheer, Vorsitzender der Gewerkschaft Handel, Banken und Versicherungen (HBV) beklagte noch 1961:

»Der Unterschied im Monatspflichtbeitrag beträgt z. B. von einer Cewerkschaft zur anderen bei gleichem Verdienst über 500 v. H. Selbst bei den beiden größten Gewerkschaften beträgt der Unterschied im höchsten Monatsbeitrag das Doppelte. Streikunterstützung: Unterschied bis zur dreifachen Leistung. Krankengeld: Unterschied bis zur vierfachen Leistung. Sterbegeld: Unterschied bis zur siebenfachen Leistung. Altersunterstützung: Unterschied in der Leistung von dreifacher Höhe. $\ll^{113}$

Die Ursache hierfür sah Vietheer in der mangelnden Autorität der Dachorganisation und in der ungenügenden Koordination zwischen den Gewerkschaften. Daher plädierte er für eine bessere Abstimmung und eine zumindest vorsichtige Annäherung im Hinblick auf Beitragshöhe und Leistungen der Gewerkschaften. ${ }^{114}$

\subsubsection{Für einen stärkeren Gewerkschaftsbund}

Die kleineren Gewerkschaften versuchten ab 1959, dem DGB mehr Aufgaben zukommen zu lassen und eine Gestaltungsmacht bei der Koordinierung möglichst vergleichbarer Beiträge und Leistungen für Mitglieder zu erreichen. Sie scheiterten jedoch an den großen Gewerkschaften, insbesondere der IG Metall, die kein Interesse an einer Stärkung des DGB hatte, weil sie über genügend Finanzkraft verfügte, um die für ihre Aufgaben erforderlichen Mittel selbstständig aufzubringen. Ohne einen starken DGB konnte die IG Metall als größte Gewerkschaft ihren Kurs und ihre politische Ausrichtung ohne Abstimmung mit anderen festlegen

113 Vietheer (1961): Koordination und Konzentration im gewerkschaftlichen Bereich, S. 163. 114 Vietheer (1961): Koordination und Konzentration im gewerkschaftlichen Bereich, S. 165. 
und hatte so aufgrund ihrer Größe und Bedeutung einen präjudizierenden Charakter für alle Gewerkschaften.

1969, nachdem die GTB unter Karl Buschmann einen Kurs der Professionalisierung und Effektivitätssteigerung des eigenen Apparates eingeschlagen hatte, forderte sie eine entsprechende Kursänderung auch für den DGB. Die Frage der zukünftigen DGB-Struktur stand dann beim 8. Ordentlichen DGB-Kongress im Mai 1969 auf der Tagesordnung. Wegen der sehr unterschiedlichen Vorstellungen sollte eine vertiefte Diskussion erfolgen. Nach einigen selbstkritischen Beiträgen, die Neuerungen anmahnten, betonte der IG Metall-Vorsitzende Otto Brenner, kein Reformfetischist zu sein, und mahnte vor zu viel Eifer in dieser Sache. ${ }^{115}$ Schließlich setzten die Befürworter mit einer knappen Mehrheit durch, dass auf einem außerordentlichen Kongress über eine neue DGB-Satzung entschieden werden solle.

Bis zu diesem Kongress, der im Mai 1971 in Düsseldorf stattfand, war Karl Buschmann zum Sprecher derjenigen avanciert, die einen klaren Reformkurs vorantrieben, der entscheidende Veränderungen vorsah. Die GTB legte dem Kongress einen kompletten neuen Satzungsentwurf vor und sparte nicht mit Kritik an den bestehenden Verhältnissen. Buschmann bestritt, dass die Gewerkschaften in ihrer damaligen Form den Mitgliedern einen größtmöglichen Nutzen brächten. Er wies darauf hin, dass es den Gewerkschaften nicht gelinge, ihren Organisationsgrad zu steigern, da die wachsende Beschäftigung keinen Niederschlag in der Mitgliederentwicklung finde. Er vermisste eine schonungslose Analyse und fragte:

»Am 1. Mai haben wir mit vielen Rednern aus fast allen Gruppen unseres Staates recht deutlich gesagt, daß gründlich und umfassend auf fast allen Gebieten geändert, neu geordnet und modernisiert werden muß. Ist der Staub der Jahre nur bei allen anderen liegen geblieben? Sollten wir nicht auch selbst kritisch genug sein und unsere Lage und unsere Verfassung einer gründlichen Untersuchung unterziehen? «116

Leidenschaftlich plädierte er dafür, zu

»vermeiden, dass gemeinsame gewerkschaftspolitische Anliegen an oder von 17 Stellen gleichzeitig und unter Umständen auch noch mit gegensätzlichen Ergebnissen behandelt werden. Dann machen wir den DGB langsam, aber sicher überflüssig. "17 $^{117}$

115 DGB: Protokoll des 8. Ordentlichen Bundeskongresses, 18.-23. Mai 1969 in München, S. 421.

116 Buschmann (1971): Wir brauchen einen starken Gewerkschaftsbund, S. 207.

117 Buschmann (1971): Wir brauchen einen starken Gewerkschaftsbund, S. 207. 
Buschmann forderte eine Einschränkung der Zuständigkeit der Einzelgewerkschaften. Deren Aufgabe sei die Vertretung der speziellen Interessen der Beschäftigten in ihrem Organisationsbereich insbesondere durch Tarifpolitik, aber auch gegenüber dem Gesetzgeber, Regierungen und Parteien. Nach dem Satzungsentwurf der GTB sollten die Einzelgewerkschaften ihre Zuständigkeit für Gesellschaftspolitik, Wirtschaftspolitik, Sozialpolitik und Kulturpolitik aufgeben und dem DGB übertragen. ${ }^{118}$ Durch mehr Gestaltungsmacht könne der DGB ein für alle Gewerkschaften einheitliches Beitrags- und Leistungswesen schaffen; die Gehalts- und Arbeitsbedingungen aller Gewerkschaften seien anzugleichen. Für die Mitglieder in benachbarten Betrieben unterschiedlicher Organisationsbereiche sei nicht nachvollziehbar, dass sich die Beiträge und Leistungen der Organisationen in der DGB-Familie teilweise erheblich unterschieden.

Anstelle der monatlich über Mitglieder und Funktionär:innen hereinbrechenden "gewerkschaftlichen Papierflut « sah der GTB-Entwurf eine einheitliche DGB-Mitgliederzeitung vor, durch die Ressourcen geschont und die politische Wirksamkeit verstärkt würde. ${ }^{119}$ Bereits auf dem vorangegangenen Ordentlichen Kongress hatte die GTB den ausgeschiedenen DGB-Vorsitzenden Ludwig Rosenberg zitiert, der angesichts der Mitgliederzeitschriften von sechzehn Gewerkschaften und dreizehn zusätzlichen periodisch erscheinenden Publikationen des DGB geschrieben hatte, diese Methode sei bestimmt die teuerste, aber zugleich auch die unwirksamste, um die Öffentlichkeit zu beeinflussen. ${ }^{120}$

Die Annahme des GTB-Vorschlags hätte eine revolutionäre Umwälzung der bundesdeutschen Gewerkschaftslandschaft bedeutet. In der Radikalität dieses Vorschlags kommt der aufgestaute Ärger angesichts der Weigerung der großen Gewerkschaften, eine Reform innerhalb des DGB auch nur ansatzweise zu diskutieren, zum Ausdruck.

Otto Brenner hielt schon die Abhaltung eines außerordentlichen Kongresses für überflüssig; auf die inhaltliche Kritik und die schwindende Organisationsstärke ging er nicht ein. Stattdessen verwies er auf die historische Entwicklung der Gewerkschaften nach 1949 und warnte, "niemand sollte so vermessen sein, Bewährtes gegen Unbekanntes einfach aufs Spiel zu setzen«. Angesichts der Delegiertenzahlen der großen Gewerkschaften sah er dem Versuch, die Zentralisierungstendenzen wiederzubeleben, »mit Gelassenheit entgegen«. Im Grunde seien der DGB und die Gewerkschaften »modern, schlagkräftig und leistungsfähig« ${ }^{121}$

118 Satzungsentwurf der GTB, in: DCB: Protokoll des 3. Außerordentlichen Bundeskongresses, 14./15. Mai 1971 in Düsseldorf, S. 54-165.

119 Buschmann (1971): Wir brauchen einen starken Gewerkschaftsbund, S. 208.

120 So der Delegierte Erich Lechtenberg, zit. nach: DCB: Protokoll des 8. Ordentlichen Cewerkschaftskongresses, 18.-23. Mai 1969 in München, S. 104.

121 Brenner (1971): Was bedeutet die Reform des DCB?, S. 209-212 (alle Zitate). 
Anstatt dem DGB mehr Kompetenzen zuzuordnen, schlug die IG Metall vor, die Beiträge der Mitgliedsgewerkschaften um 0,5 Prozentpunkte auf 12,5 Prozent von deren Einnahmen zu erhöhen, aber die kleinen Gewerkschaften verhinderten die Umsetzung dieses Vorschlags.

Wie schon zehn Jahre zuvor wurde die Chance vertan, die Gewerkschaftsbewegung durch eine bessere Aufgabenteilung schlagkräftiger zu machen und ihre Ressourcen effektiver einzusetzen. Zwar erlebten die DGB-Gewerkschaften in den 1970er Jahren auf den Wogen des Reformklimas und der besseren Rahmenbedingungen nochmals einen Aufschwung, der so manches Strukturproblem überdeckte. Langfristig wurden jedoch die Weichen in Richtung Bedeutungsverlust gestellt. Bereits vor fünfzig Jahren prophezeite Karl Buschmann, dass man sich das Ende des DGB ausrechnen könne, wenn sich die Aufgabenverteilung nicht grundlegend ändere. ${ }^{122}$ Ausschlaggebend für die Nicht-Reform war die »überbetonte Selbstständigkeit« der großen Gewerkschaften, wie der HBV-Vorsitzende Heinz Vietheer betonte. ${ }^{123}$ Mit ihrer Delegiertenmacht konnten IG Metall und die Gewerkschaft Öffentliche Dienste, Transport und Verkehr (ÖTV) diese ihren Wirkungsbereich einschränkenden Vorschläge leicht abwehren.

In der Öffentlichkeit wurde der Kongress mit Enttäuschung aufgenommen. Der DGB-Vorsitzende Heinz Oskar Vetter versuchte das Nicht-Ergebnis positiv zu interpretieren, indem er betonte: „Dieser Satzungskongress war kein Abschluss der Gewerkschaftsreform, sondern deren Anfang. ${ }^{124}$ In der Folge legte die GTB ihren Schwerpunkt auf die eigene Organisation, ging in der Beitragsfrage jedoch erneut in Konflikt mit den anderen DGB-Gewerkschaften (siehe Kapitel 4.4.3).

Auch auf dem Gebiet der Publikationen beließ es die GTB nicht bei Ansprüchen an den DGB, sondern suchte angesichts der Erfolglosigkeit auf DGB-Ebene, die Ineffektivität der vielen Zeitschriften für Mitglieder und Funktionär:innen zu reduzieren, nach »kleinen Lösungen«. Ab 1973 gab sie mit der Gewerkschaft Nahrung-Genuss-Gaststätten (NGG), die eine ähnliche Mitgliederzahl hatte, eine gemeinsame Mitgliederzeitung heraus. Die Titel blieben zwar mit »textil-bekleidung« und »einigkeit« weiterhin eigenständig, aber die Hälfte der Zeitschrift mit den übergeordneten Themen aus der allgemeinen Wirtschafts- und Sozialpolitik und dem Kultur- und Serviceteil wurde gemeinsam publiziert; die restlichen Seiten behandelten organisationsspezifische Themen. Beide Gewerkschaften hatten zuvor schon organisationspolitisch zusammengearbeitet, insbesondere bei der Beitragsregelung und der Einführung einer privaten Familien-Rechtsschutzversi-

\footnotetext{
122 Buschmann (1971): Wir brauchen einen starken Gewerkschaftsbund, S. 209.

123 Vietheer (1971): Zur Diskussion um die DGB-Reform - groß oder klein - ist das ein Problem?, S. 203.

124 DGB: Protokoll des 3. Außerordentlichen Bundeskongresses, 14./15. Mai 1971 in Düsseldorf, S. 291.
} 
cherung. Im DGB vertraten sie gemeinsam »gemäßigte«, sozialpartnerschaftlich ausgerichtete Positionen.

\subsubsection{Der große Sprung: Die Beitragsreform}

Der hohe Betreuungsaufwand aufgrund der Klein- und Mittelbetriebsstruktur mit nur wenigen von der Arbeit freigestellten Betriebsratsmitgliedern musste durch die Beiträge der GTB-Mitglieder finanziert werden. Die Streiks der 1950er Jahre hatten schwer an den finanziellen Reserven der Gewerkschaft gezehrt. Ab Mitte der 1960er Jahre sanken die Beschäftigtenzahlen, wodurch auch das Reservoir für Mitgliederwerbung kleiner wurde. An klassischen Textilstandorten gingen die Beschäftigtenzahlen aufgrund von Rationalisierung in den Großbetrieben zurück. Neue Standorte der Bekleidungsindustrie wurden in eher ländlichen Gebieten gegründet, die ein niedrigeres Lohnniveau versprachen und den Unternehmen bislang nichterwerbstätige Frauen als Arbeitskräfte erschlossen. Die GTB musste ihre Strukturen diesen Entwicklungen anpassen.

Ausgehend von einer umfassenden »organisatorischen Bestandsaufnahme« stellte sie ab 1967 eine regelmäßige "mittelfristige Organisations- und Finanzplanung « auf. ${ }^{125}$ Für alle Verwaltungsstellen wurde das Organisationspotenzial ermittelt, also die Anzahl der Beschäftigten den erreichten Mitgliederzahlen gegenübergestellt. So wurden die für die Mitgliederbetreuung und -werbung relevanten Strukturdaten erfasst und Organisationsgrade sowie durchschnittliche Beitragshöhen transparent. Damit hatte der Hauptvorstand die Möglichkeit, bei Bedarf gezielt zu intervenieren. Beispielsweise wurden Werbe- und Finanzpläne mit den Verwaltungsstellen erarbeitet und der Personaleinsatz gezielt gesteuert.

Zwischen dem Notwendigen und dem Möglichen stand jedoch die Finanzkraft und die war nicht im Überfluss vorhanden. Ein schwerwiegendes Problem stellte das sinkende Verhältnis zwischen Mitgliedsbeiträgen und Einkommen dar. In der Gründungsphase Anfang der 1950er Jahre betrug der Wochenbeitrag die Höhe eines Stundenlohns, was einer Beitragshöhe von mehr als 2 Prozent des Monatseinkommens entsprach. Innerhalb eines Jahrzehnts sank der tatsächlich gezahlte Beitrag auf durchschnittlich 1,5 Prozent des Monatseinkommens.

Seit Gewerkschaften gegründet wurden, hat das tendenziell sinkende Verhältnis zwischen Gewerkschaftsbeitrag und Lohn Tradition. Der von einem Gewerkschaftsmitglied zu entrichtende Anteil war im Kaiserreich höher als in der Weimarer Republik und in den 1920er Jahren höher als 1970. ${ }^{126}$ Hinzu kamen technische Probleme: In Zeiten der Lohnauszahlung in bar, gingen die ehrenamtlichen Kassierer:innen von Mitglied zu Mitglied und verkauften Beitragsmarken, aber

125 GTB (1991): textil-bekleidung. 100 Jahre GTB. Sonderausgabe zum Jubiläum, S. 160.

126 Streeck (1978): Politischer Wandel und organisatorische Reformen, S. 590. 
in den 1960er Jahren stellten immer mehr Betriebe auf bargeldlose Lohnzahlung um. Außerdem hatten die Beitragsmarken eine Staffelung in 50-Pfennig-Schritten, so dass Beitragserhöhungen einen deutlich spürbaren Sprung bedeuteten. In der Folge wurden sie immer weniger akzeptiert, weil der Beitrag als fester Betrag und nicht im Verhältnis zum Lohn begriffen wurde. Bis 1969 war die effektive Beitragshöhe auf durchschnittlich 0,75 Prozent der Bruttoeinkommen gesunken, obwohl er laut Satzung ungefähr 1,4 Prozent des Lohnes betragen sollte. Der GTB drohte schließlich der finanzielle Kollaps. ${ }^{127}$

Organisatorisch setzte die GTB darauf, dass die Beiträge direkt durch die Lohnbüros einbehalten und an sie überwiesen wurden. Wo dies nicht verpflichtend geschah oder die Arbeitgeber nicht bereit dazu waren, wurde das Lastschriftverfahren eingesetzt. Diese Einzugsarten brachten organisatorische Erleichterungen, lösten allerdings nicht die finanziellen Schwierigkeiten. Deshalb beschloss ein außerordentlicher Gewerkschaftstag 1970 eine grundlegende Beitragsreform: Formal wurde der Beitrag auf 1 Prozent des Bruttomonatseinkommens gesenkt und damit der Anspruch verbunden, dass diese Beitragshöhe nicht verhandelbar war. Die Konsequenz daraus war, dass nur Mitglied bleiben konnte, wer den Beitrag auch in dieser Höhe zahlte. Effektiv wurden die Beiträge durch diese Maßnahme um fast die Hälfte erhöht.

Mit dieser Reform waren neue Gewerkschaftsleistungen verbunden. Die GTB nahm die bereits von mehreren Gewerkschaften eingeführte Freizeitunfallversicherung in ihr Leistungsangebot auf. Ein neuer Ansatz war die eingeführte Familien-Rechtsschutzversicherung für private Angelegenheiten. Damit reagierte man auf zunehmende Angebote von Versicherungen, die einen solchen Schutz teilweise im Verbund mit dem Rechtsschutz im Arbeits- und Sozialrecht anboten, der eine gewerkschaftliche Standardleistung war. Durch den Gruppenvertrag für 300.000 Mitglieder konnte die GTB diese Versicherung für einen Bruchteil des Beitrags für individuelle Versicherungsverträge finanzieren. Außerdem wurde das Streikgeld mit dem neuen System angehoben und entsprach nun dem Nettoeinkommen - ein Beitrag zur Förderung der Streikfreudigkeit, die die GTB auszeichnete.

Dennoch war die vom außerordentlichen Gewerkschaftstag getroffene Entscheidung mit hohem Risiko verbunden und wurde auch in Gewerkschaftskreisen als ambitioniert oder schlicht undurchführbar angesehen. ${ }^{128}$ Dem GHV war es gelungen, durch eine breite Diskussion in der Gewerkschaft die satzungsbildende Mehrheit für sein Vorhaben zu bekommen. Unkalkulierbar blieb, wie groß die Mitgliederverluste sein würden. Der Geschäftsbericht beschreibt die Umsetzung als einen »Kampf gegen in Jahrzehnten gewachsene Vorurteile, aber

127 GTB: Geschäftsbericht 1968-1970 des Hauptvorstandes, S. 176.

128 GTB: Geschäftsbericht 1968-1970 des Hauptvorstandes, S. 175. 
auch einen Kampf für die Schlagkraft und Handlungsfähigkeit unserer Organisation «. ${ }^{129}$ Trotzdem sollte dieses dynamische, dauerhaft an die Einkommen und damit an die Einkommensentwicklung gekoppelte Beitragssystem durchgesetzt werden, und zwar ohne Ausnahmen, da alle Zugeständnisse wie das Akzeptieren von Übergangslösungen die Reform insgesamt gefährdet hätten.

1971, im Jahr der Umsetzung dieser Reform, verlor die GTB 18.000 Mitglieder und damit rund 6 Prozent ihrer Mitgliedschaft. Zwei Jahre später, Ende 1973, war der Mitgliederverlust trotz eines gleichzeitigen Abbaus von 80.000 Arbeitsplätzen in den Branchen Textil und Bekleidung nicht nur wettgemacht, die GTB hatte ihre Mitgliederzahl von Ende 1970 sogar überschritten. Damit war die Organisation auf eine neue, deutlich stabilere finanzielle Basis gestellt. Der Durchschnittsbeitrag erhöhte sich von 6,46 DM im Jahr 1970 auf 9,17 DM in 1971 und stieg bis 1975 auf 12,71 DM. ${ }^{130}$ Durch das dynamische System wirkten sich die durchgesetzten Tariferhöhungen in vollem Umfang auf die Beitragshöhe aus. Die Beitragseinnahmen, die 1970 ein Volumen von 18,8 Millionen DM umfassten, erhöhten sich bereits 1971 auf 24,8 Millionen DM und stiegen bis 1975 auf 38,1 Millionen DM - sie hatten sich innerhalb von vier Jahren also verdoppelt. ${ }^{131}$

Allen Unkenrufen zum Trotz hatte die GTB bewiesen, dass eine grundsätzliche Beitrags- und Organisationsreform möglich ist und dass es sogar durchsetzbar war, die Satzungsbestimmungen über die Beitragshöhe nicht nur als »unverbindliche Preisempfehlung « zu betrachten. Doch zunächst folgten nur die ÖTV und die NGG diesem Beispiel. Die IG Metall hatte noch bis Ende der 1970er Jahre mit im Verhältnis zu den Einkommen sinkenden Mitgliedsbeiträgen zu kämpfen und führte erst $\mathrm{ab} 1979$ die verbindliche 1-Prozent-Regelung ein. ${ }^{132}$ Daher zahlten die Mitglieder der Textil-Bekleidungs-Gewerkschaft einen höheren Beitrag als die meisten Metaller:innen. Der Durchschnittsbeitrag betrug Ende 1973 in der GTB 10,92 DM, ${ }^{133}$ während die IG Metall stolz war, dass sie bei insgesamt höheren Einkommen ihrer Mitglieder 10,08 $\mathrm{DM}^{134}$ erreicht hatte.

Die gestiegenen Beitragseinnahmen hatten zur Folge, dass die GTB höhere Beiträge pro Mitglied an den DGB zu überweisen hatte als die IG Metall und alle anderen Mitgliedsgewerkschaften, nämlich laut DGB-Satzung 12 Prozent der Beitragseinnahmen. Nachdem die Bemühungen gescheitert waren, ein einheitliches Beitragssystem für die Mitglieder in den DGB-Gewerkschaften zu schaffen (siehe Kapitel 4.4.2), verweigerte die GTB die Zahlung der geforderten 12 Prozent

\footnotetext{
129 GTB: Geschäftsbericht 1968-1970 des Hauptvorstandes, S. 175.

130 GTB: Geschäftsbericht 1974-1978 des Hauptvorstandes, S. 211.

131 GTB: Geschäftsbericht 1974-1978 des Hauptvorstandes, S. 215.

132 GTB: Geschäftsbericht 1974-1978 des Hauptvorstandes, S. 209.

133 GTB: Geschäftsbericht 1971-1973 des Hauptvorstandes, S. 205.

134 IG Metall: Geschäftsbericht 1971-1973, S. 475.
} 
ihrer neuen, deutlich höheren Einnahmen und war nur zu einer Zahlung entsprechend ihrer Mitgliederzahl in der Höhe der Durchschnittsbeiträge aller DGB-Gewerkschaften bereit. Wenn es in der Entscheidungsfreiheit jeder Gewerkschaft liege, wie hoch ihre Beiträge seien, sei eine einheitliche prozentuale Abführung an den DGB ungerecht. ${ }^{135}$

Auf dem DGB-Kongress 1972 beantragten GTB und NGG Satzungsänderungen, die bei der Beitragsleistung an den DGB die Organisationsstruktur und das Verhältnis des Durchschnittsbeitrags zum Durchschnittseinkommen ihrer Mitglieder berücksichtigten. ${ }^{136}$ Die Anträge fanden keine Mehrheit, stattdessen definierte die beschlossene Satzungsänderung, was unter »Beitragsaufkommen«als Messgröße für den DGB-Beitrag zu verstehen war, denn die GTB hatte »vorsichtshalber« schon 1971 beschlossen, ihr Beitragsaufkommen als Grundlage für den DGB-Beitrag um einen jährlich festzulegenden Organisationsfaktor zu bereinigen, also per definitionem zu verringern. Von diesem korrigierten »Beitragsaufkommen « sollten dann die 12 Prozent an den DGB gezahlt werden. ${ }^{137}$

Dies setzte die GTB um und kürzte die Ausgangsbasis für den DGB-Beitrag um 20 Prozent. Nach heftigen Auseinandersetzungen mit Zahlungsaufforderungen und Rechtsgutachten beider Seiten fanden der DGB-Bundesausschuss und die GTB schließlich im September 1972 - ein Vierteljahr nach dem Bundeskongress - einen Kompromiss. Dieser enthielt zum einen die Aufforderung an den DGB-Bundesvorstand, "sich darum zu bemühen, dass in allen DGB-Gewerkschaften einheitlich die Mitgliedsbeiträge in einem Prozentsatz zum Verdienst festgelegt und die Unterstützungen und Leistungen der Gewerkschaften einander angeglichen werden ${ }^{138}$ zum anderen wurde der GTB für die Jahre 1971 bis 1973 ein Beitragsrabatt von 1,5 Millionen DM eingeräumt. ${ }^{139}$ Nach und nach folgten alle Gewerkschaften dieser von der »kleinen GTB« kreierten Linie eines dynamischen und verbindlichen Mitgliedsbeitrags.

Neben der Verbesserung der Einnahmen wurden durch die neuen Kassierungssysteme für die Beiträge weitere finanzielle Ressourcen geschaffen, denn die eingeführten bargeldlosen Einzugsarten waren kostengünstig. Im Jahr 1965 wurden noch 50 Prozent der Beiträge durch Unterkassierer:innen in den Betrieben oder durch Hauskassierung eingenommen, wovon ein Inkassobeitrag in Höhe von 5 Prozent bei den ehrenamtlichen Kassierer:innen verblieb. 1973 wurden nur noch 15 Prozent der Beiträge auf diesem Weg entrichtet. Bei 69 Prozent der

135 CTB: Ceschäftsbericht 1971-1973 des Hauptvorstandes, S. 191.

136 Antrag 438 in: DCB: Protokoll des 9. Ordentlichen DCB-Kongresses, 25.-30. Juni 1972 in Berlin, S. 141.

137 CTB: Geschäftsbericht 1971-1973 des Hauptvorstandes, S. 192.

138 CTB: Ceschäftsbericht 1971-1973 des Hauptvorstandes, S. 196.

139 GTB: Geschäftsbericht 1971-1973 des Hauptvorstandes, S. 197. 
Mitglieder zogen die Lohnbüros der Unternehmen die Gewerkschaftsbeiträge direkt vom Lohn oder Gehalt ab. Die restlichen Mitglieder bezahlten ihre Beiträge per Bankeinzug oder -überweisung, so dass die Beitragszahlung in bar im Laufe der 1970er Jahre bedeutungslos wurde.

Von den Beitragseinnahmen verblieben 15 Prozent in den lokalen GTB-Verwaltungsstellen, die hiervon ihre Kosten für Büro, Mitgliederbetreuung und -werbung, Schulungsmaßnahmen und sonstige Verwaltung zu tragen hatten. Die Personalkosten wurden vom Hauptvorstand übernommen. Etwaige Überschüsse verblieben im Bereich der Verwaltungsstellen und wurden als sogenannter Verwaltungsstellen-Kassenbestand oder Verwaltungsstellenvermögen deren Rücklage. Die Überschüsse aus der Verwendung der übrigen 85 Prozent, über die der Hauptvorstand verfügte, bildeten als Rücklage für Arbeitskämpfe den Streikfonds.

Durch die anteilige Teilhabe der Verwaltungsstellen verbesserte die Beitragsreform deren Einnahmesituation. Die Verwaltungsstellen hatten jedoch ganz unterschiedliche strukturelle Voraussetzungen, was die Größe des Betreuungsgebiets, die Branchenstruktur und die Betriebsgrößen anging. Hinzu kamen in der Hochzinsphase der 1970er Jahre hohe Einnahmen für diejenigen, die ein Verwaltungsstellenvermögen hatten. Die 1-Prozent-Regelung bei der Beitragszahlung hatte zur Folge, dass der jährliche Vermögenszuwachs aller Verwaltungsstellen von 74.000 DM im Jahr $1969^{140}$ auf 532.000 DM in 1973 anstieg. Doch aufgrund der strukturellen Unterschiede schwankten die Verwaltungsstellen-Kassenbestände stark und betrugen zwischen o und 266.000 DM. Während eine Reihe von Verwaltungsstellen im Laufe der Zeit immer »reicher« wurde, mussten strukturschwache Verwaltungsstellen bald vom Hauptvorstand unterstützt werden, um ihre Aufgaben überhaupt wahrnehmen zu können. 1974 betrug der Jahresbedarf dieser Zuschüsse 850.000 DM. ${ }^{141}$

Besonders "reich« waren die Verwaltungsstellen in den Textilzentren des Münsterlandes. Um die Situation der »armen« Verwaltungsstellen zu verbessern, gelang es dem Hauptvorstand, viele der finanzstarken Verwaltungsstellen für eine Reform zu gewinnen, die ihre Einnahmen beschneiden würde, denn gegen die Delegierten der »reichen« Verwaltungsstellen war eine Satzungsänderung nicht realisierbar. Dank der breiten Diskussion im Vorfeld ging es in der entsprechenden Debatte auf dem Gewerkschaftstag 1974 nur noch um die Ausgestaltung der Reform. Mit der erforderlichen Zweidrittelmehrheit wurde festgelegt, dass jeder Verwaltungsstelle anstatt der bisherigen 15 Prozent nur noch 10 Prozent der

140 GTB: Geschäftsbericht 1968-1970 des Hauptvorstandes, S. 185.

141 GTB: Protokoll des 12. Ordentlichen Cewerkschaftstages, 3.-8. November 1974 in München, S. 221. 
Beitragseinnahmen garantiert und die »eingesparten« 5 Prozent aufgrund von Strukturmerkmalen auf die Verwaltungsstellen verteilt würden. ${ }^{142}$

Im Ergebnis hieß das, dass Verwaltungsstellen mit einer großen Flächenausdehnung und kleinen Betriebsgrößen bis zu 20 Prozent ihrer Beitragseinnahmen erhielten, während sich Verwaltungsstellen mit Großbetriebsstrukturen auf engem Raum mit 11 Prozent begnügen mussten. Dass diese Neuregelung passgenau war, zeigte die Entwicklung der Folgejahre: Von 1974 bis 1977 nahmen die Kassenbestände der beitragsabgebenden Verwaltungsstellen immerhin noch um $523.000 \mathrm{DM} \mathrm{zu}$ (plus 20,4 Prozent), die Kassenbestände der Empfänger von zusätzlichen Beitragsanteilen stiegen mit 958.000 DM auf mehr als das Doppelte (plus 126,9 Prozent). ${ }^{143}$

\subsubsection{Offensive "Vorwärtsstrategie»}

Auch wenn die Größenordnung des künftigen Beschäftigungsabbaus Ende der 1960er Jahre noch nicht einmal zu erahnen war, wusste man doch, dass die weitere Automatisierung der Textilproduktion und die wachsenden Importe unweigerlich zum Arbeitsplatzabbau führen würden. Die GTB stand vor der Frage, ob sie sich organisatorisch auf die Anpassung an diese Verhältnisse einstellen sollte. Der Hauptvorstand schlug eine andere Richtung ein und entwickelte eine "Vorwärtsstrategie«: Die sinkende Tendenz beim Organisationsgrad sollte gestoppt und die »Nichtmitglieder-Reserve« von rund zwei Drittel der Beschäftigten erschlossen werden.

Mit der Beitragsreform (siehe Kapitel 4.4.3) war ein Teil dieser Strategie umgesetzt worden. ${ }^{144}$ Der dadurch gewonnene finanzielle Spielraum konnte für den Kern der »Vorwärtsstrategie«, den Ausbau des hauptamtlichen Teams, eingesetzt werden. Bei bislang 170 hauptamtlich tätigen »politischen Sekretär:innen« wurde die Neueinstellung von 30 weiteren, möglichst unter 30-jährigen Sekretär:innen beschlossen. Durch die Reformen war es möglich geworden, die Personalstärke im Jahrzehnt des rapiden Beschäftigungseinbruches nicht nach unten anpassen zu müssen, sondern die durch die Politik gesetzten günstigeren Rahmenbedingungen mit zusätzlichem Personal zu nutzen. Bis 1979 wuchs die Gruppe der politischen Sekretär:innen auf den Höchststand von 199 Personen, darunter 16 Frauen - 1971 waren es noch 11 weibliche Hauptamtliche gewesen. ${ }^{145}$

142 GTB: Protokoll des 12. Ordentlichen Cewerkschaftstages, 3.-8. November 1974 in München, S. 225.

143 CTB: Geschäftsbericht 1974-1977 des Hauptvorstandes, S. 221.

144 GTB: Ceschäftsbericht 1971-1973 des Hauptvorstandes, S. 206.

145 GTB: Ceschäftsbericht 1978-1981 des Hauptvorstandes, S. 274. 
So nutzte die GTB die Möglichkeiten des 1972 reformierten Betriebsverfassungsgesetzes systematisch und intensiv. Dieses bot erleichterte Möglichkeiten, erstmalige Betriebsratswahlen auch extern anstoßen zu können, so dass die GTB bei den Betriebsratswahlen 1975 mit 2.706 Betriebsratsbetrieben einen absoluten Höchststand erreichte. In 477 Betrieben wurde erstmals ein Betriebsrat gewählt, und damit zugleich die Voraussetzungen für eine bessere gewerkschaftliche Mitgliederrekrutierung geschaffen. Damit waren 73 Prozent aller Beschäftigten in der Textil- und der Bekleidungsindustrie in Betrieben mit Betriebsrat beschäftigt, in der Textilindustrie allein betrug dieser Anteil sogar 85 Prozent. ${ }^{146}$

In den 1970er Jahren wanderten 130.000 Arbeitsplätze der Bekleidungsindustrie in Billiglohnländer oder fielen dem Kulturwandel im Bekleidungsverhalten zum Opfer. Trotz dieses Aderlasses blieb die GTB-Mitgliederzahl der in der Bekleidungsindustrie Beschäftigten während des ganzen Jahrzehnts konstant. Dass die Betriebsratsgremien durchaus einen Rückhalt bei den Beschäftigten hatten, zeigt die Wahlbeteiligung von 83,1 Prozent.

Entscheidende Bedeutung für die Betriebsratsgremien hatte eine Neuerung, den die Betriebsverfassungsreform geschaffen hatte. Betriebsratsmitglieder hatten erstmals einen gesetzlichen Anspruch auf bezahlte Freistellung für Qualifizierungsmaßnahmen. Betrafen diese »erforderliches Betriebsratswissen«, hatten die Arbeitgeber neben der Weiterzahlung des Entgelts auch alle weiteren Kosten, also Reise-, Übernachtungs- und Seminarkosten zu tragen. ${ }^{147}$ Darüber hinaus erhielt jedes Betriebsratsmitglied in der dreijährigen Legislaturperiode das Recht auf drei bzw. vier Wochen Bildungsurlaub; ${ }^{148}$ hier hatte der Arbeitgeber nur den Verdienstausfall zu tragen.

Die GTB nutzte beide Bestimmungen, und startete eine Qualifizierungsoffensive. Den strategischen Schwerpunkt legte sie auf Bildungsurlaubsseminare in Form von Wochenkursen, die sie ortsnah anbot. Verpflegungs- und Reisekosten wurden von der GTB übernommen, was die Durchsetzung der Freistellung gerade in kleineren Familienbetrieben erleichterte, da die Kostenbelastung der Arbeitgeber begrenzt blieb. Ein weiterer bedeutender Effekt war die Seminarteilnahme von Frauen, denn viele Frauen scheuten die Abwesenheit von zu Hause für einen Zeitraum von ein oder zwei Wochen, die beim Besuch eines Seminars an einer zentralen Bildungsstätte erforderlich war. Teilweise war eine solche Abwesenheit wegen fehlender Möglichkeiten zur Kinderbetreuung nicht zu organisieren, teilweise standen Frauen unter dem Druck ihrer Ehepartner, die ihre Frauen nicht »ohne Aufsicht« allein reisen lassen wollten. Bei den örtlichen Seminaren

146 CTB: Ceschäftsbericht 1974-1977 des Hauptvorstandes, S. 439ff.

$147 \S 37$ Absatz 6 Betriebsverfassungsgesetz.

$148 \S 37$ Absatz 7 Betriebsverfassungsgesetz. 
konnten die Teilnehmerinnen zu Hause übernachten, wodurch diese Probleme vermieden wurden.

Die regionalen Seminare wurden von Gewerkschaftssekretär:innen vor Ort geleitet. Der Hauptvorstand hatte ein Bildungskonzept erarbeitet und stellte den Referent:innen umfangreiche Materialien zur Verfügung. Durch die Kenntnis der betrieblichen Problemlagen fanden die Seminare praxisbezogen statt. Nicht nur Wissen wurde vermittelt, auch konkrete Umsetzungsstrategien konnten erarbeitet werden. Ebenfalls vor dem Hintergrund der konkreten Situation in den Betrieben verband die GTB jedes Seminar mit Mitgliederwerbung. Insgesamt überwog der Vorteil der Praxiskenntnis und -nähe den Nachteil, dass die Referent:innen kaum über fundierte Kenntnisse in der Erwachsenenpädagogik verfügten.

Neben dem breiten Angebot auf örtlicher Ebene baute die GTB ihre Bildungsstätte, die Werner-Bock-Schule in Beverungen/Weserbergland aus. 1975 eröffnete sie eine zweite zentrale Bildungsstätte in Rottach-Egern am Tegernsee und unterstrich mit der 1977 eröffneten Kritischen Akademie in Inzell (siehe Kapitel 4.2) ihre Ansprüche und Kompetenz in gewerkschaftlicher Bildungspolitik.

Um dem Ziel gerecht zu werden, die Mehrheit der Betriebsratsmitglieder mit ihren Seminaren zu erreichen, ging die GTB auch unorthodoxe Wege. Die Arbeitgeber, die trotz aller sozialpartnerschaftlichen Ansätze der Gewerkschaft befürchteten, sich verstärkt konfliktgestärkten Betriebsräten gegenüberzusehen, versuchten in einigen Bundesländern, eigene Seminare für Betriebsratsmitglieder anzubieten. Im Bezirk Baden-Württemberg wollten sie die Sozialpartnerschaft auf die Probe stellen und bekundeten ihr Interesse, an den von der GTB angebotenen Bildungsmaßnahmen beteiligt zu werden. Die GTB stimmte unter der Voraussetzung zu, dass die Arbeitgeber im Gegenzug auf eigene Angebote verzichteten. Der Hauptvorstand beschloss, dass bei Wochenseminaren außer am ersten und letzten Tag eine Beteiligung erfolgen könne, und zwar in der Form

»dass ein Arbeitgeber- und ein Cewerkschaftsreferent abwechselnd die im Lehrplan vorgesehenen Themen behandeln und gemeinsam mit den Schulungsteilnehmern besprechen . $^{149}$

Zeitanteilig hatte der Arbeitgeberverband die Seminarkosten zu übernehmen. Über diesen Weg, der teilweise auch im Bezirk Nordrhein praktiziert wurde, wurde die Hürde weiter gesenkt, die Freistellung betrieblich durchzusetzen, schließlich konnten die Betriebsräte darauf hinweisen, dass durch die Arbeitgeberreferent:innen eine gewisse Ausgewogenheit gewährleistet sei. Allerdings war dieser Weg nicht nur bei den Arbeitgeberverbänden, sondern auch in der GTB umstrit-

149 GTB: Geschäftsbericht 1971-1973 des Hauptvorstandes, S. 117. 
ten, so dass der Einsatz von Arbeitgeberreferent:innen auf Dauer nur in BadenWürttemberg stattfand.

Die Bildungsoffensive der GTB war bundesweit erfolgreich; die örtlichen Seminare erwiesen sich geradezu als Renner. 1972 und 1973 führten die Verwaltungsstellen der GTB über 3.000 Bildungsveranstaltungen mit über 60.000 teilnehmenden Mitgliedern durch. ${ }^{150}$ Wie die Zahlen aus der nächsten Wahlperiode belegen, war die Bildungsoffensive auch kein Strohfeuer: Bei den Betriebsratswahlen 1975 wurden 14.959 Betriebsratsmitglieder gewählt; während der dreijährigen Legislaturperiode zählte die GTB 25.322 Teilnehmer:innen an regionalen, in der Regel einwöchigen Seminaren - viele besuchten also mehrere Seminare. Zusätzlich nahmen 6.363 Betriebsratsmitglieder an den zentralen Seminaren der beiden GTB-eigenen Bildungsstätten teil. ${ }^{151}$ Dabei ist zu berücksichtigen, dass in den durch Klein- und Mittelbetriebe geprägten Branchen nur 19,1 Prozent der Betriebsratsgremien das Recht hatten, mindestens ein Betriebsratsmitglied vollständig von der beruflichen Tätigkeit freizustellen, und nur in jedem dritten dieser Betriebe gab es mehrere freigestellte Betriebsratsmitglieder.

Die GTB systematisierte im Rahmen ihrer »Vorwärtsstrategie« die Mitgliederwerbung weiter. Dafür erarbeitete sie Jahres- und mittelfristige Ziele auf Grundlage der geschätzten Fluktuationsverluste sowie der angestrebten Organisationsgradverbesserung und unter Einbezug von Prognosen für die Branchenentwicklung. Diese vom Hauptvorstand beschlossenen Zielsetzungen wurden über die Gewerkschaftsbezirke und Verwaltungsstellen bis auf die Betriebsebene heruntergebrochen. Statt einer schematischen Verteilung wurden aufgrund der jeweiligen Gegebenheiten vor Ort für jeden Betrieb Ziele und Umsetzungsstrategien festgelegt. ${ }^{152}$ Die Zielerreichung aller Verwaltungsstellen wurde monatlich in Form von Bestenlisten an alle Verwaltungsstellen verschickt.

Insbesondere die konfliktorientierten Tarifrunden wurden für die Mitgliederwerbung genutzt. In den Jahren 1971 bis 1973 erfolgten 35 Prozent der Beitritte während der Tarifauseinandersetzungen. ${ }^{153}$ Von 1970 bis 1979 nahm die GTB 517.242 neue Mitglieder auf, wodurch sie statistisch gesehen ihren kompletten Mitgliederbestand zweimal erneuerte. Die sogenannte relative Werbequote, das Verhältnis der Neuaufnahmen zu allen beschäftigten Nichtmitgliedern, stieg von unter 10 Prozent jährlich auf knapp 15 Prozent. ${ }^{154}$ Das Rekordjahr war $1973 \mathrm{mit}$ 68.848 neuen Mitgliedern (23 Prozent des Mitgliederbestandes), wodurch sich der

\footnotetext{
150 GTB: Geschäftsbericht 1971-1973 des Hauptvorstandes, S. 119.

151 GTB: Geschäftsbericht 1974-1977 des Hauptvorstandes, S. $191 \mathrm{ff}$.

152 GTB: Geschäftsbericht 1971-1973 des Hauptvorstandes, S. 386.

153 GTB: Geschäftsbericht 1971-1973 des Hauptvorstandes, S. 385.

154 GTB: Geschäftsbericht 1978-1981 des Hauptvorstandes, S. 314.
} 
Mitgliederbestand um 13.332 erhöhte (plus 4,5 Prozent), bei gleichzeitigem Rückgang der Beschäftigung um 25.000 (minus 4 Prozent).

Angesichts der kontinuierlichen Arbeitsplatzverluste in der Textilindustrie hatte die GTB ihren Schwerpunkt auf die Verbesserung ihrer Präsenz in der Bekleidungsindustrie gelegt - der Branche, die in den ersten zwei Nachkriegsjahrzehnten oft im Schatten der Textilindustrie stand. Sie hatte Erfolg und verbesserte ihren Organisationsgrad im Bekleidungsbereich in den 1970er Jahren von 22 Prozent auf 33 Prozent und in den 1980er Jahren auf 39 Prozent.

\subsection{Karl Buschmann - der große Steuermann der GTB}

Karl Buschmann hatte die Politik der Gewerkschaft Textil-Bekleidung seit ihrer Gründung mitgeprägt, zunächst als Bezirksleiter in Ostwestfalen, seit 1951 als Tarifverantwortlicher im Geschäftsführenden Hauptvorstand (GHV) und seit 1963 als Vorsitzender. Zum Ende der Amtszeit von Werner Bock positionierte er sich immer stärker als »Modernisierer« gegenüber der Riege alter Sozialdemokrat:innen traditioneller Ausrichtung. Er war der Kopf der Funktionär:innen, die die ursprünglich durch klassenkämpferische Töne geprägten GTB neu ausrichteten und zu einer Arbeitnehmervertretung machten, die ein sozialpartnerschaftliches Miteinander propagierte. Diese Linie wurde während Buschmanns Amtszeit von der Mehrheit in der Organisation getragen. Die grundsätzliche Auseinandersetzung um die politische Ausrichtung, die fünf Jahre nach seiner Wahl zum Vorsitzenden den Gewerkschaftstag 1968 geprägt hatte, fand 1971 auf dem Dortmunder Kongress nicht mehr statt.

Dies wirkte sich besonders auf die Wahlen zum GHV aus. Mit 196 von 209 abgegebenen Stimmen erreichte Karl Buschmann 1971 eine Zustimmung von 93,8 Prozent und damit das beste Ergebnis, das ein GTB-Vorsitzender jemals erhalten hatte. Bei seiner letztmaligen Wahl 1974 erreichte er immer noch herausragende 193 Stimmen (92,3 Prozent). Wenn auch ein Teil der GTB-Mitglieder der sozialpartnerschaftlichen Linie weiterhin kritisch gegenüberstand, so trug man diese Auseinandersetzung nicht mehr mit dem Stimmzettel gegenüber dem Vorsitzenden aus. Unter den schwieriger gewordenen Rahmenbedingungen war dies vor allem auch ein Hinweis der Geschlossenheit in Richtung Arbeitgeber und Politik.

Die politischen Differenzen zeigten sich aber noch bei den Wahlergebnissen der geschäftsführenden Vorstandsmitglieder, wenn auch weniger stark als 1968 (siehe Kapitel 4.1.6). 1971 erhielt Martin Heiß, der »schwarze« Stellvertretende Vorsitzende, 69, 0 Prozent der Stimmen und Walter Schongen, der zweite Christlich-Soziale im GHV nur 58,4 Prozent. Mit Paul Trost schied 1971 das letzte GHVMitglied aus dem Führungsgremium aus, das bereits 1949 dem ersten Geschäfts- 
führenden Hauptvorstand angehört hatte. Ihm, dem einst der kommunistischen Wühlarbeit Verdächtigten, folgte mit Hans Pfister (85,6 Prozent) ein ehemaliger "Traditionalist«, der aber ins Buschmann-Lager gewechselt war.

Die Mehrheit der nun sechs "Gemäßigten« im GHV wurde hin und wieder durch die »Linke« Gerda Linde (79,4 Prozent) gestört, die 1969 für den verstorbenen Martin Lange in das Führungsgremium nachgewählt worden war. Berthold Keller, führender Wendestratege der 1950er Jahre, wurde während der Legislaturperiode durch den Beirat nachgewählt und stand 1974 das erste Mal auf einem Gewerkschaftstag zur Wahl. Hier erhielt er mit 152 Stimmen (72,7 Prozent) das schlechteste Ergebnis, noch hinter der »Linken« Gerda Linde, die 172 Stimmen $(82,3$ Prozent) bekam.

Objektiv gesehen gab es gute Gründe, Karl Buschmann zu stützen. Trotz der grundsätzlich auf Partnerschaft angelegten Strategie hatte der Hauptvorstand unter seiner Führung die von den regionalen Tarifkommissionen ausgehende aktive Tarifpolitik nicht eingegrenzt, im Gegenteil: Immer wieder genehmigte er Urabstimmungen, um den Druck zu erhöhen, und auch Streiks wurden nicht gescheut. Dass mit den Tarifverbesserungen in den großen Branchen wie der Metall- und Elektroindustrie Schritt gehalten wurde, führte zu einer hohen Zufriedenheit der GTB-Mitglieder mit ihrer Gewerkschaft. Angesichts der Unfähigkeit der Arbeitgeber, wirksame Gegenstrategien zu entwickeln, konnte diese ihre finanziellen Risiken in Arbeitskämpfen begrenzen und sich mit Nadelstichen durchsetzen. Die Ausnahme bildet der Arbeitskampf im Jahr 1965 um die Mitgliedervorteilsregelungen, der mit einer Niederlage endete (siehe Kapitel 4.1.3). Insgesamt stiegen die Einkommen im Textil- und im Bekleidungssektor in mehreren Etappen prozentual stärker an als im Durchschnitt aller Industriebereiche.

Der Arbeitsplatzabbau in der Textil- und der Bekleidungsindustrie in den 1970er Jahren war rasant. Insgesamt gingen rund 360.000, d.h. 41 Prozent der Arbeitsplätze verloren. Strukturprobleme drückten die Branche; steigende Einkommen kamen eher anderen Konsumgütern und Autoherstellern zugute. $\mathrm{Zu}$ sätzlich drückte die Produktivitätsentwicklung bei stagnierenden Absätzen die Beschäftigung. Der Umsatz pro Beschäftigtem stieg in den 1970er Jahren bei Textil von 54.000 DM auf 116.000 DM, in der Bekleidungsindustrie von 41.000 DM auf 89.000 DM (siehe Tabellen 8 und 9 im Anhang).

Ein immer entscheidenderer Faktor wurden die Importe. Zwar gelang es der bundesdeutschen Textil- und Bekleidungsindustrie, auch ihren Export deutlich zu steigern, dennoch stieg der Importüberschuss von 3 Milliarden DM im Jahr 1971 auf 11 Milliarden DM in 1980 (siehe Tabelle 11 im Anhang). Die GTB setzte auf vielfältige politische Aktivitäten zur Arbeitsplatzsicherheit. Diese waren zwar nur beschränkt wirksam, aber damit blieb die Organisation auch außerhalb der Tarifrunden sichtbar und bezog ihre Mitglieder mit ein. 
Trotz dieser widrigen Umstände blieb die GTB stabil und handlungsfähig. Der gewerkschaftliche Organisationsgrad stieg von 34,4 Prozent im Jahr 1971 auf 49,0 Prozent in 1980. Der trotzdem durch den Beschäftigungsabbau bedingte Mitgliederrückgang führte nicht zu finanziellen Schwierigkeiten, im Gegenteil: Die jährlichen Beitragseinnahmen erhöhten sich in diesem Zeitraum von 19,1 Millionen DM auf 50,5 Millionen DM. Die Anzahl der mit politischen Aufgaben betrauten Gewerkschaftssekretär:innen stieg in den 1970er Jahren von 169 auf $194 .{ }^{155}$

Es ist bemerkenswert: Die Gewerkschaft mit praktisch allen strukturell negativen Voraussetzungen - ein Wirtschaftssektor mit relativ kleinen Betriebsgrößen, ein hoher Frauenanteil an den Beschäftigten, die höchste Fluktuationsrate und ein radikaler Beschäftigungsabbau - hatte beim Organisationsgrad nicht nur den Durchschnitt aller Gewerkschaften im DGB erreicht, sondern diesen deutlich überschritten. Während sich bei allen DGB-Gewerkschaften das Verhältnis der Mitglieder zu den Beschäftigten in den 1970er Jahren von 36,3 Prozent auf 39,0 Prozent entwickelt hatte, ${ }^{156}$ war der Organisationsgrad bei der GTB auf 49, 0 Prozent gestiegen.

Karl Buschmann festigte die sozialpartnerschaftlich ausgerichtete Koalition aus gemäßigten Sozialdemokraten und Christlich-Sozialen. Mit ihnen rüstete er den Arbeitgebern gegenüber verbal ab, ohne tarifpolitische Leisetreterei zu betreiben. Er machte die GTB zur anerkannten Sprecherin der Branche und baute einen Draht zu Bundeskanzler Helmut Schmidt auf, stellte aber zugleich gegenüber der sozialliberalen »Wunschregierung« eine konsequente Interessenvertretung unter Beweis.

Ein entscheidender Erfolg Buschmanns war die Professionalisierung der eigenen Organisation, nachdem sein großes Anliegen, die grundsätzliche Reform des DGB, gescheitert war. Mutige Entscheidungen erwiesen sich als richtig. Das »Organisationswunder«, mit dem die GTB unter Karl Buschmann viele Gewerkschaften im Organisationsgrad überrundete, war das Ergebnis einer gezielten Strategie und systematisch betriebener Arbeit. Die solide Finanzgrundlage ermöglichte die Nutzung neuer gesetzlicher Möglichkeiten, genügend Personal und eine beteiligungsorientierte Tarif- und Branchenpolitik. Die hohen Beitrittszahlen sind Beleg für die Verbundenheit und Motivation der ehrenamtlich Aktiven. Auf dem Gewerkschaftstag 1978 trat Buschmann nach fünfzehn Jahren im Vorsitz altersbedingt nicht mehr zur Wiederwahl an und stellte rückblickend fest:

»Voller Vertrauen blicken die Beschäftigten [...] auf unsere Entscheidungen. Dass wir ein großes Vertrauenskapital angesammelt haben, beweist die Mitgliederentwicklung. Obwohl in den letzten vier Jahren annähernd 200.000 Arbeitsplätze in

155 GTB: Geschäftsberichte des Hauptvorstandes.

156 Greef (2014): Cewerkschaften im Spiegel von Zahlen, Daten und Fakten, S. 699. 
unseren Wirtschaftszweigen verlorengingen, konnten wir den Mitgliederstand fast halten. Ich kann hier wohl zu Recht feststellen, dass die Überzeugungskraft und die Glaubwürdigkeit unserer Politik mit eine entscheidende Voraussetzung für diese hervorragende organisatorische Leistung war.« ${ }^{157}$

Karl Buschmann starb am 16. Februar 1988 im Alter von 73 Jahren in seiner Geburtsstadt Bielefeld.

157 GTB: Protokoll des 13. Ordentlichen Gewerkschaftstages, 1.-6. Oktober 1978 in Mannheim, S. 9. 